\title{
Ecological divergence and medial cuneiform morphology in gorillas
}

\author{
Matthew W. Tocheri ${ }^{\mathrm{a}, *}$, Christyna R. Solhan ${ }^{\mathrm{a}, \mathrm{b}}$, Caley M. Orr ${ }^{\mathrm{a}}$, John Femiani ${ }^{\mathrm{c}}$, Bruno Frohlich ${ }^{\mathrm{d}}$, \\ Colin P. Groves ${ }^{\text {, }}$, William E. Harcourt-Smith ${ }^{\text {f,g }}$, Brian G. Richmond ${ }^{\mathrm{a}, \mathrm{b}}$, Brett Shoelson ${ }^{\mathrm{h}}$, \\ William L. Jungers ${ }^{\mathrm{i}}$
}

\author{
${ }^{a}$ Human Origins Program, Department of Anthropology, National Museum of Natural History, Smithsonian Institution, 10th and Constitution Avenue NW, Washington, \\ DC 20013-7012, USA \\ ${ }^{\mathrm{b}}$ Center for the Advanced Study of Hominid Paleobiology, Department of Anthropology, The George Washington University, 2110 G Street NW, Washington, DC 20052, USA \\ ${ }^{\mathrm{c}}$ Department of Engineering, Arizona State University - Polytechnic, 7231 E. Sonoran Arroyo Mall, Peralta Hall, Room 230U, Mesa, Arizona 85212-0180, USA \\ ${ }^{\mathrm{d}}$ Department of Anthropology, National Museum of Natural History, Smithsonian Institution, 10th and Constitution Avenue NW, Washington, DC 20013-7012, USA \\ e School of Archaeology and Anthropology, Building 14, Australian National University, Canberra, ACT 0200, Australia \\ ${ }^{\mathrm{f}}$ Department of Anthropology, Lehman College, Bronx, New York \\ ${ }^{g}$ Division of Paleontology, American Museum of Natural History, New York, NY, USA \\ ${ }^{\mathrm{h}}$ The MathWorks, 3 Apple Hill Drive, Natick, Massachusetts 01760-2098, USA \\ ${ }^{\mathrm{i}}$ Department of Anatomical Sciences, Stony Brook University Medical Center, Stony Brook, New York 11794-8081, USA
}

\section{A R T I C L E I N F O}

\section{Article history:}

Received 5 April 2010

Accepted 15 August 2010

\section{Keywords:}

Hallux

Tarsals

Functional morphology

Laser scanning

CT scanning

3D morphometrics

\begin{abstract}
A B S T R A C T
Gorillas are more closely related to each other than to any other extant primate and are all terrestrial knuckle-walkers, but taxa differ along a gradient of dietary strategies and the frequency of arboreality in their behavioral repertoire. In this study, we test the hypothesis that medial cuneiform morphology falls on a morphocline in gorillas that tracks function related to hallucial abduction ability and relative frequency of arboreality. This morphocline predicts that western gorillas, being the most arboreal, should display a medial cuneiform anatomy that reflects the greatest hallucial abduction ability, followed by grauer gorillas, and then by mountain gorillas. Using a three-dimensional methodology to measure angles between articular surfaces, relative articular and nonarticular areas, and the curvatures of the hallucial articular surface, the functional predictions are partially confirmed in separating western gorillas from both eastern gorillas. Western gorillas are characterized by a more medially oriented, proportionately larger, and more mediolaterally curved hallucial facet than are eastern gorillas. These characteristics follow the predictions for a more prehensile hallux in western gorillas relative to a more stable, plantigrade hallux in eastern gorillas. The characteristics that distinguish eastern gorilla taxa from one another appear unrelated to hallucial abduction ability or frequency of arboreality. In total, this reexamination of medial cuneiform morphology suggests differentiation between eastern and western gorillas due to a longstanding ecological divergence and more recent and possibly non-adaptive differences between eastern taxa.
\end{abstract}

Published by Elsevier Ltd.

\section{Introduction}

Gorillas are predominantly terrestrial knuckle-walkers in terms of their locomotor patterns, but all also include a variable suite of arboreal behaviors in their respective positional repertoires (Tuttle, 1970; Tuttle and Watts, 1985; Langdon, 1986; Hunt, 1991; Remis, 1994, 1998; Sarmiento, 1994; Goldsmith, 1996; Sarmiento et al., 1996). Among gorillas, Gorilla beringei beringei (the mountain gorilla) ${ }^{1}$ is

\footnotetext{
* Corresponding author.

E-mail address: tocherim@si.edu (M.W. Tocheri).

1 We follow the taxonomy proposed by Groves $(2000,2001,2003)$ and the common names proposed by Tuttle (2003), which together recognize two species, G. beringei (eastern gorillas) and G. gorilla (western gorillas), and probably four subspecies, G. b. beringei, G. b. graueri, G. g. gorilla, and G. g. diehli, referred to as mountain, grauer, western, and Cross River gorillas, respectively.
}

the least arboreal and Gorilla gorilla gorilla (the western gorilla) is the most arboreal (Doran and Hunt, 1994; Remis, 1994, 1998). Mountain gorillas live in high-altitude habitats made up of dwarf montane forest where their primary food source is terrestrial herbaceous vegetation, a resource that is abundant throughout this environment (Groves, 1970, 1971; Fossey and Harcourt, 1977; Doran, 1996; Doran and McNeilage, 1998, 2001). Because fruit resources are scarce and trees are small and discontinuous, mountain gorillas do not often leave the ground to forage. Instead they travel and forage within their daily range almost exclusively terrestrially (Schaller, 1963; Groves, 1970, 1971; Tuttle, 1970; Fossey and Harcourt, 1977; Tuttle and Watts, 1985; Doran, 1996; Doran and McNeilage, 1998). In contrast, western gorillas reside in lower-altitude habitats (Tuttle, 1970; Remis, 1994, 1998; Goldsmith, 1996; Doran and McNeilage, 1998; Goldsmith, 


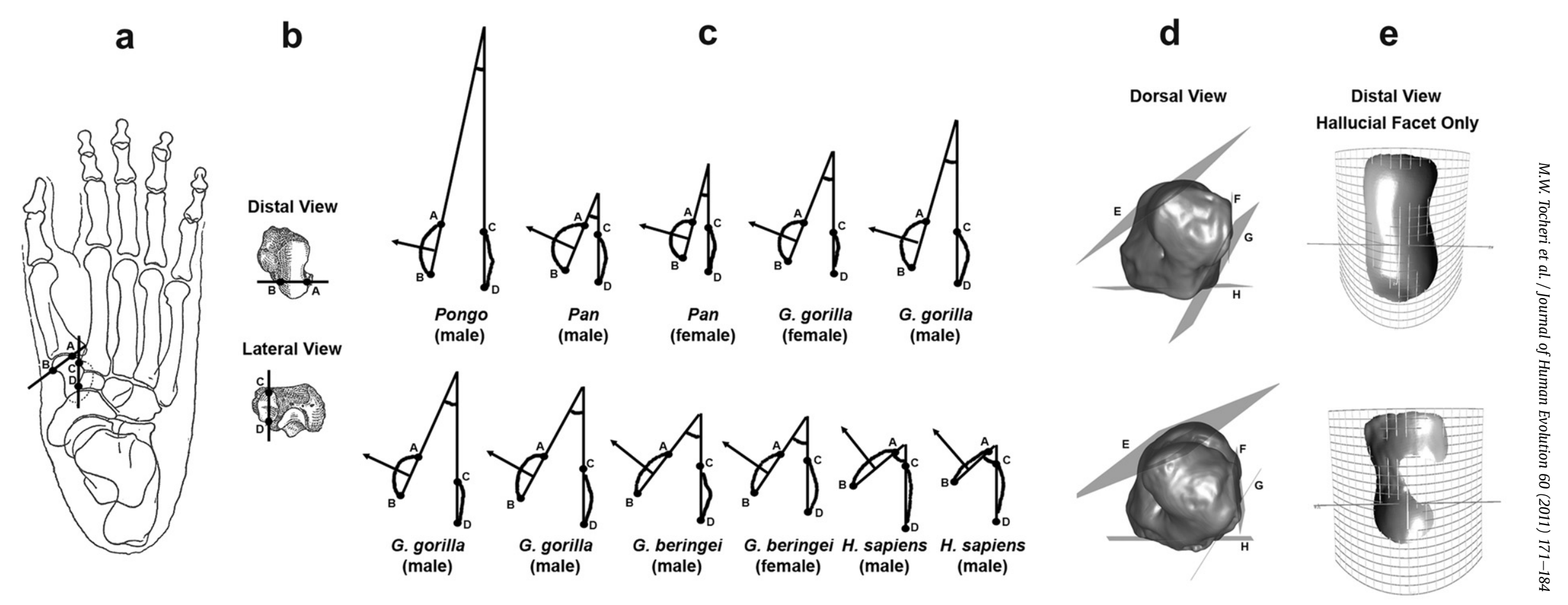

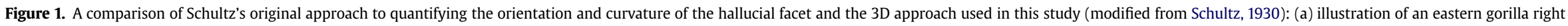

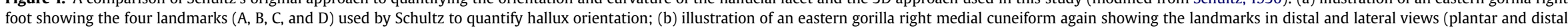

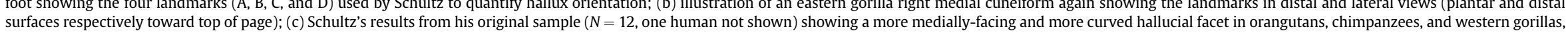

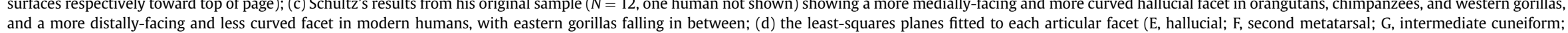

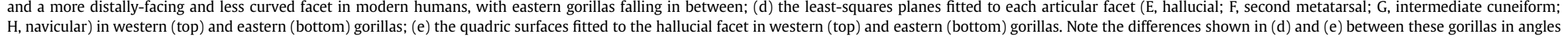
between planes and facet curvatures exemplify several of the functional predictions described in the text. 


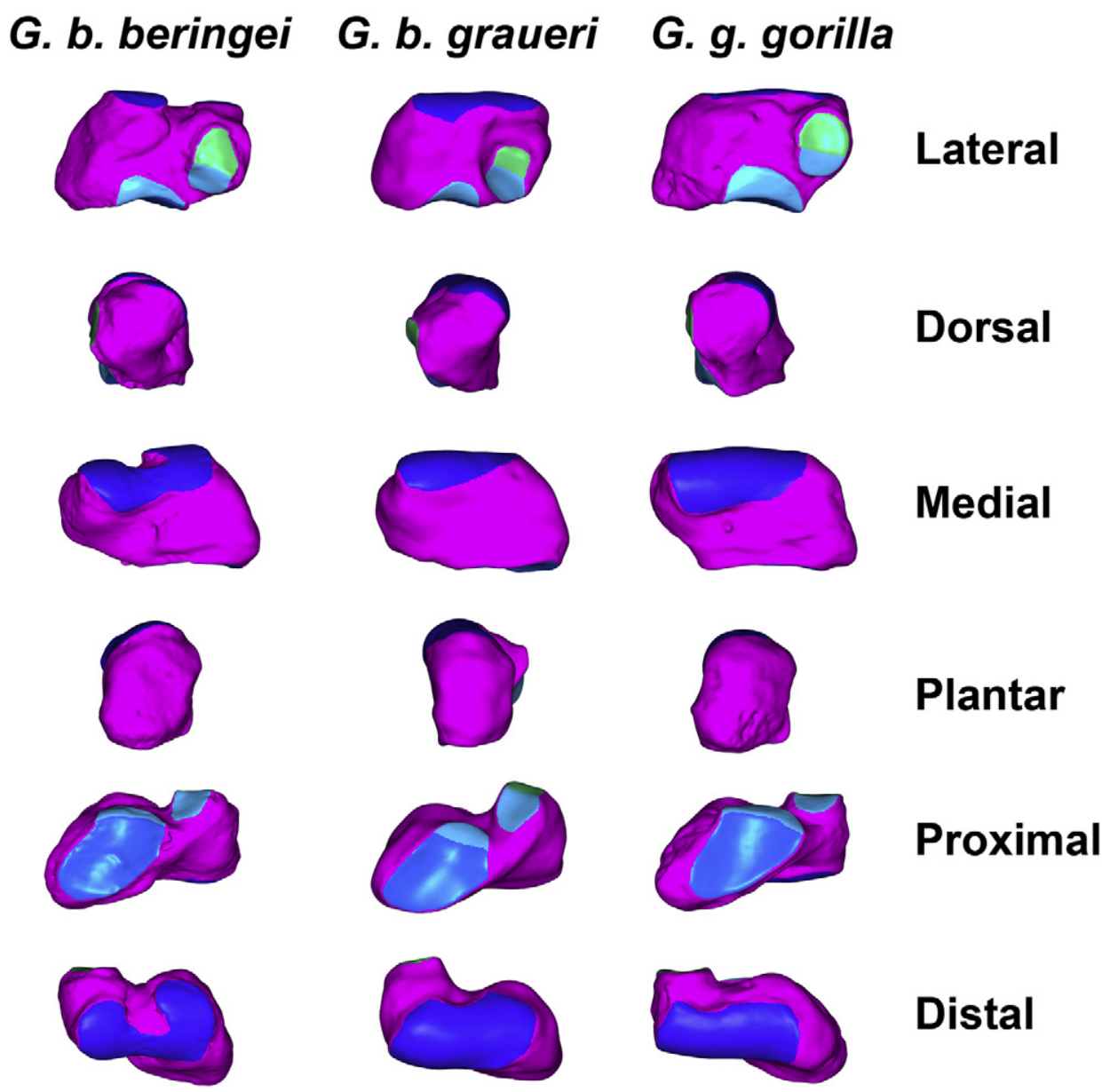

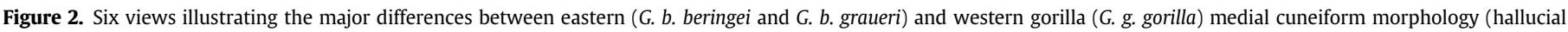

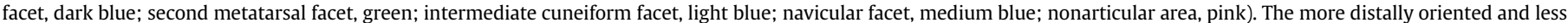

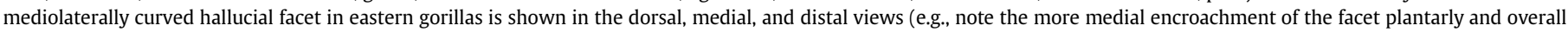

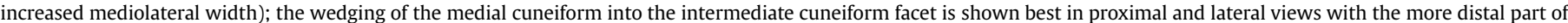



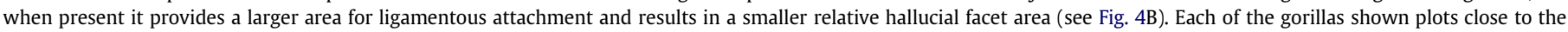
center of their respective multivariate clusters (Figs. 5 and 9).

1999). These continuously forested, high-canopy habitats provide western gorillas with opportunities to exploit different seasonal fruit resources, as well as opportunities to build tree nests on top of readily available arboreal supports (Tuttle, 1970; Tuttle and Watts, 1985; Tutin et al., 1991; Tutin and Fernandez, 1993; Remis, 1994, 1998; Goldsmith, 1996, 1999; Doran and McNeilage, 1998). Consequently, these gorillas incorporate a considerable amount of climbing and prehensile grasping into their positional repertoire when moving between feeding locations (Tutin et al., 1991; Remis, 1994, 1998; Doran, 1996; Goldsmith, 1996, 1999).
Gorilla beringei graueri (the grauer gorilla) inhabits both high and low-altitude habitats (Schaller, 1963; Groves, 1967, 1970, 1971) in the east-central portion of the Democratic Republic of Congo. Populations from Mt. Tshiaberimu, Mt. Kahuzi, and the Itombwe Mountains, live in high-altitude habitats similar to those of mountain gorillas. In contrast, other populations inhabit more loweraltitude habitats known as the Utu region, which is west of the mountainous regions, going towards, but not reaching, the Lualaba River. Grauer gorillas living in highland habitats rely primarily on terrestrial herbaceous vegetation and bamboo, similar to mountain

Table 1

Sample sizes by taxon, sex, and museum collection for gorillas used in this study ${ }^{\mathrm{a}}$

\begin{tabular}{|c|c|c|c|c|c|c|c|}
\hline \multirow[t]{3}{*}{ Collection } & \multicolumn{2}{|c|}{ Mountain } & \multicolumn{2}{|c|}{ Grauer } & \multicolumn{3}{|c|}{ Western } \\
\hline & \multicolumn{2}{|c|}{ Gorilla beringei beringei } & \multicolumn{2}{|c|}{ Gorilla beringei graueri } & \multicolumn{3}{|c|}{ Gorilla gorilla gorilla } \\
\hline & Male & Female & Male & Female & Male & Female & Unknown \\
\hline United States National Museum & $5(4)$ & 2 & & & $5(4)$ & $3(3)$ & 1 \\
\hline Royal Museum for Central Africa & 2 & 4 & 7 & 6 & 1 & 1 & \\
\hline Academy of Natural Sciences, Philadelphia & & & & & $1(1)$ & $2(2)$ & \\
\hline Total by Sex & $7(4)$ & 6 & 7 & 6 & $7(5)$ & $6(5)$ & 1 \\
\hline Total by Taxon & & & & & & $14(10)$ & \\
\hline
\end{tabular}

${ }^{a}$ Numbers in parentheses indicate the number of specimens from which both left and right medial cuneiforms were scanned (see text for details). 

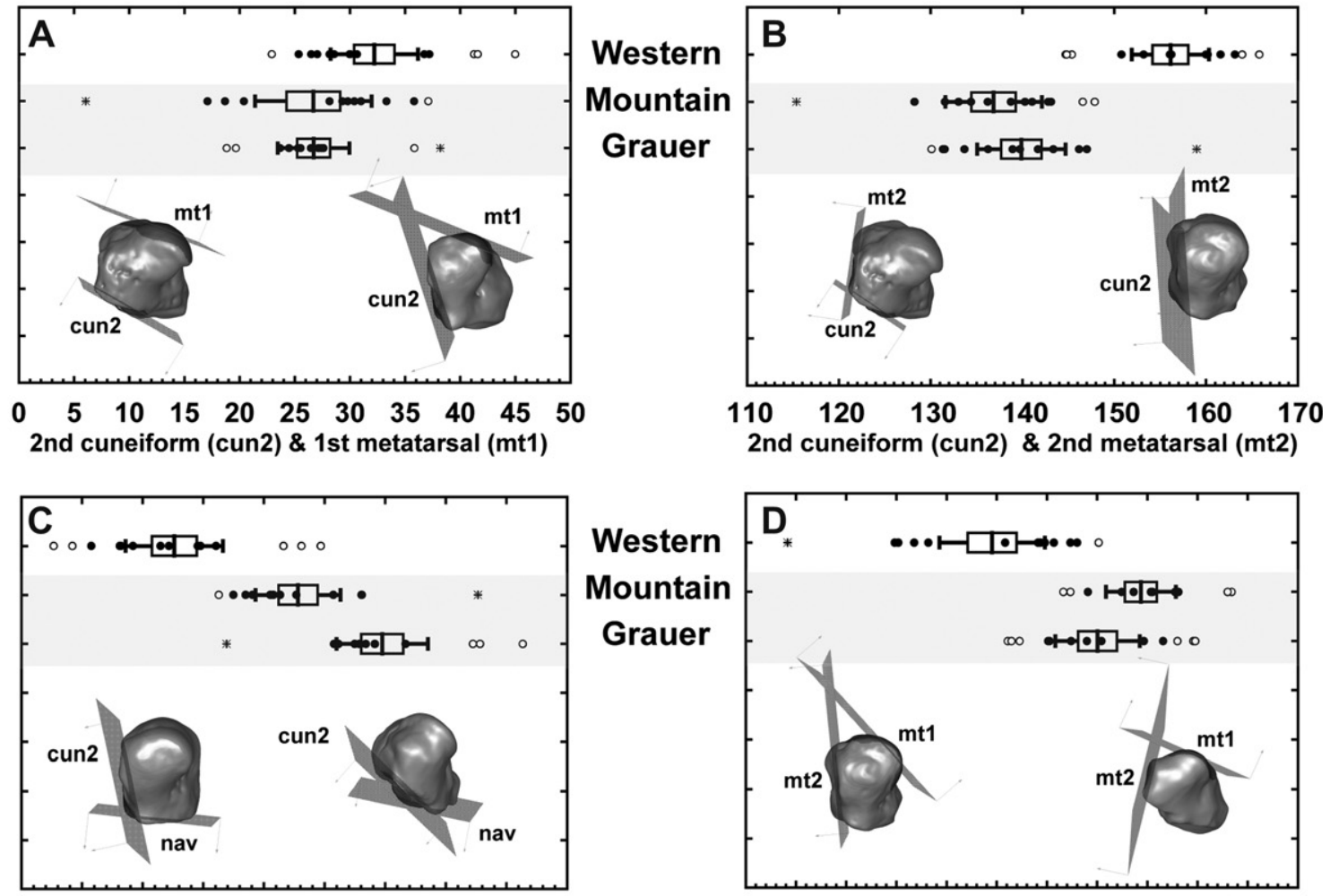

105110115120125130135140145150 2nd cuneiform (cun2) \& navicular (nav)

$\begin{array}{llllllllllll}30 & 35 & 40 & 45 & 50 & 55 & 60 & 65 & 70 & 75 & 80 & 85\end{array}$ 1st metatarsal (mt1) and 2nd metatarsal (mt2)
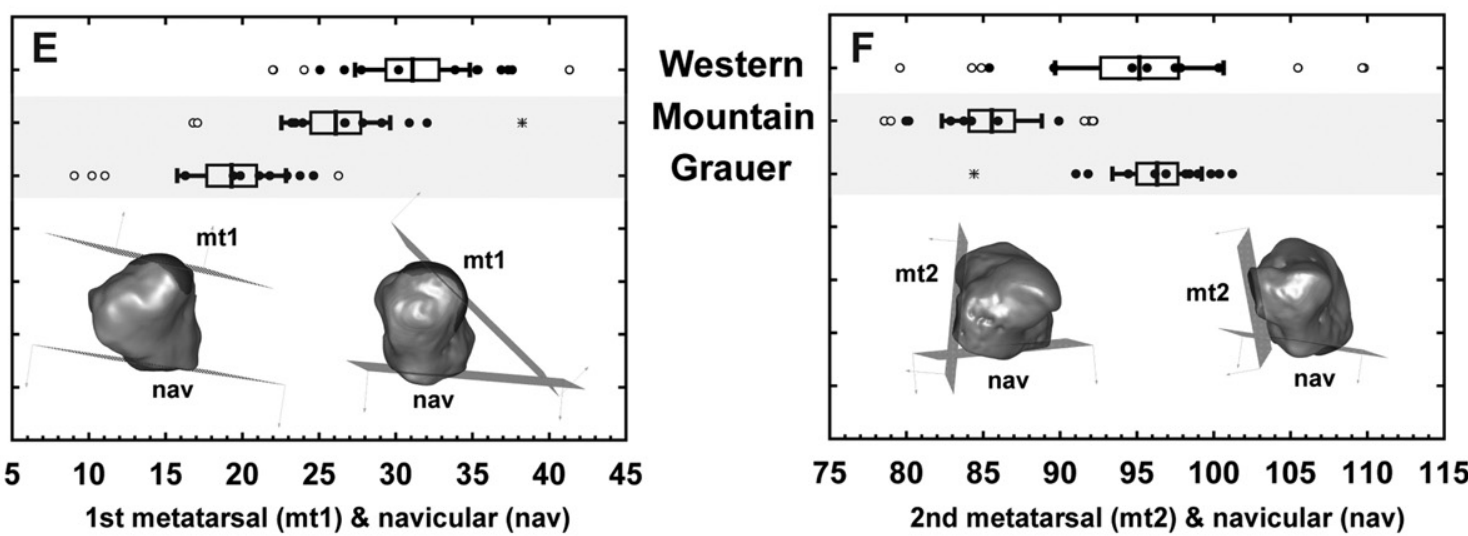

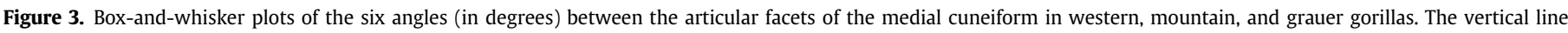

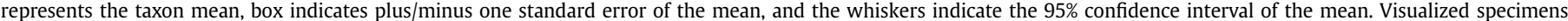
represent values toward the extremes along each axis to demonstrate the shape changes that occur with differing angle values.

gorillas, whereas those living in the lowland Utu region have seasonally frugivorous diets and utilize more extensive ranging patterns similar to western gorillas (Yamagiwa et al., 1992, 1996; Yamagiwa and Mwanza, 1994; Uchida, 1996; Doran and McNeilage, 1998; Jabbour, 2008). For example, grauer gorillas inhabiting the low-altitude montane forest of the Kahuzi-Biega National Park forage extensively for fruit during times of seasonal availability and engage in extensive bouts of climbing in order to access these resources (Casimir, 1975; Goodall and Groves, 1977; Yamagiwa and Mwanza, 1994).

Overall, the extent of continuously forested areas and the availability of key dietary resources appear to directly impact how gorilla taxa engage in arboreal behaviors. In fact, habitat differences explain why foraging strategies, resource exploitation, and frequencies of arboreality are more similar between western gorillas and sympatric chimpanzees than they are between highland and lowland gorillas (Remis, 1994, 1998; Yamagiwa and Mwanza, 1994; Goldsmith, 1996, 1999; Yamagiwa et al., 1996; Doran and McNeilage, 1998). Thus, the behavioral and ecological evidence suggests that eastern gorillas are generally more terrestrial and less arboreal than western gorillas, and among eastern gorillas, mountain gorillas are on average more terrestrial and less arboreal than grauer gorillas. If adaptive morphological evolution in gorillas is tied to these ecological factors, then morphological features facilitating locomotion in the trees, such as those that relate to prehensile grasping during climbing (e.g., hallucial abduction capability), might be expected to fall on a morphocline reflecting a continuum of substrate use (Jabbour, 2008).

A principal determinant of hallucial abduction ability is the orientation of the medial cuneiform's hallucial joint surface in 

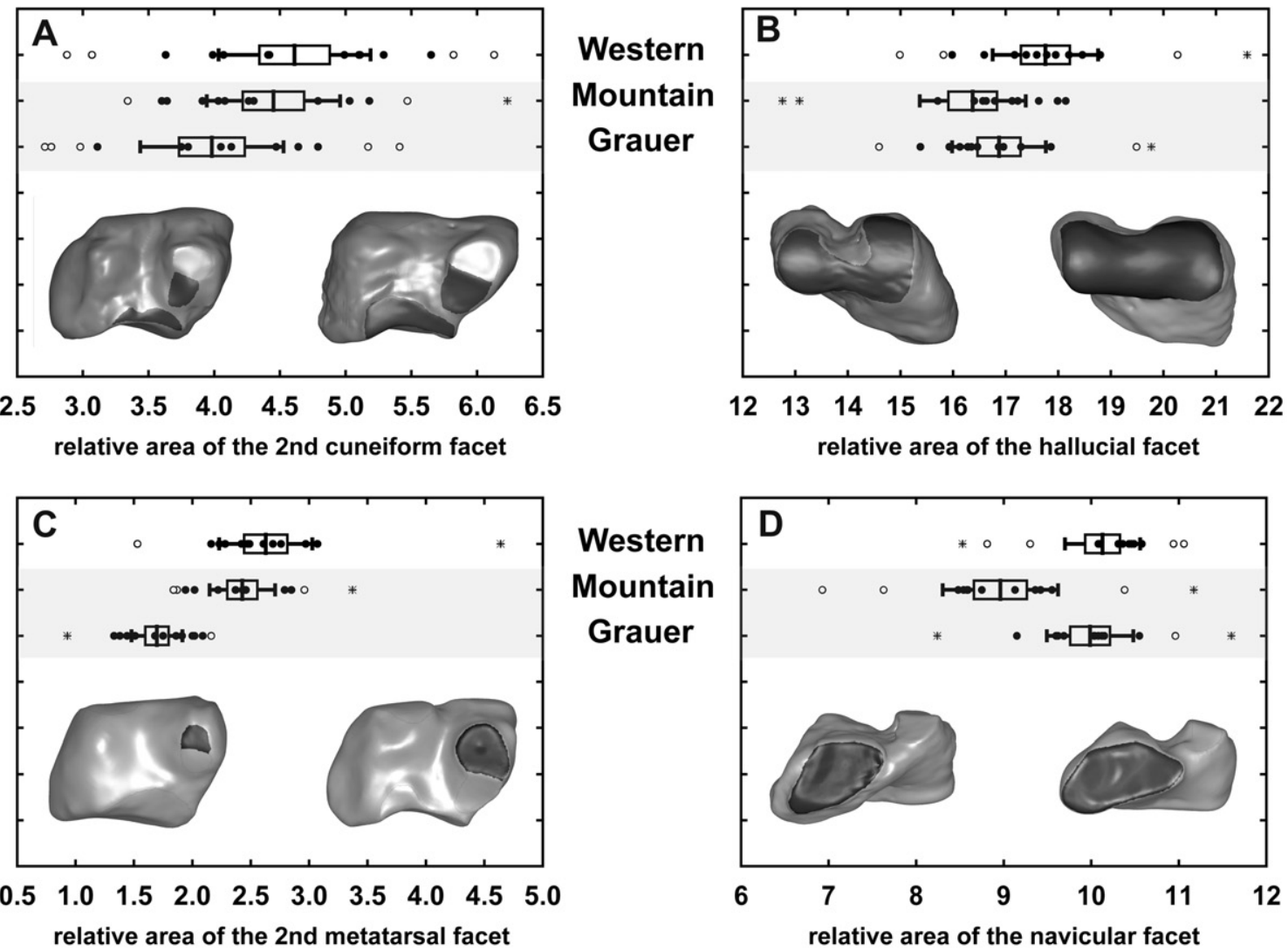

relative area of the 2 nd metatarsal facet
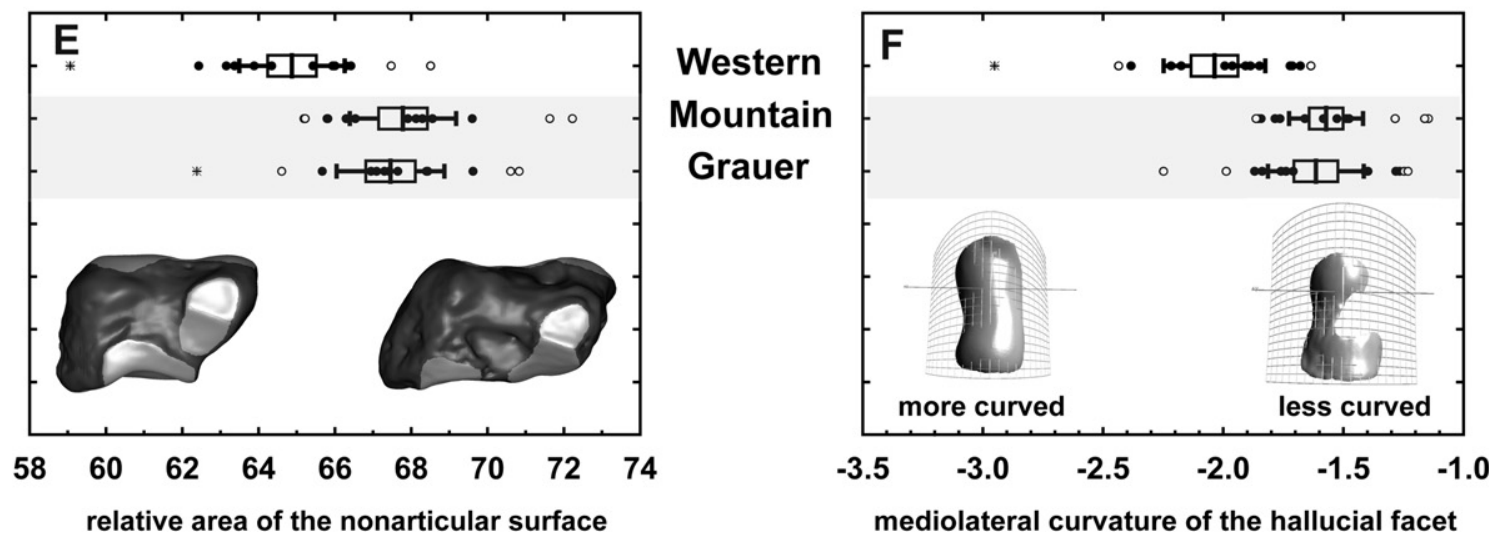

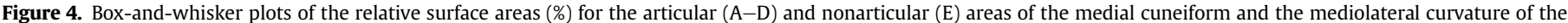

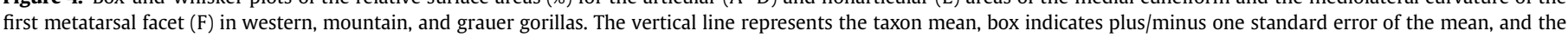

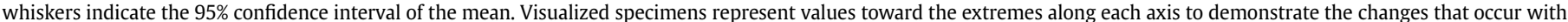
differing values.

relation to the longitudinal axis of the foot (Schultz, 1930, 1934; Tuttle, 1970; Gomberg, 1981; Gebo, 1992). Based on a total sample of 12 humans and great apes, Schultz $(1930,1934)$ first noted that hallux orientation was more similar in chimpanzees and western gorillas relative to orangutans on the one hand and mountain ${ }^{2}$ gorillas and modern humans on the other (Fig. 1). Hallux orientation is partially attributed to the degree of medial tilt displayed by the first metatarsal facet on the medial cuneiform (Schultz, 1930, 1934; Gomberg, 1981; McHenry and Jones, 2006). In great apes, the medial tilt of this facet is oblique relative to the proximodistal

\footnotetext{
2 Note that Schultz's (1930) 'mountain' gorilla sample of two included one mountain gorilla and one grauer gorilla from Mt. Kahuzi.
}

axis of the medial cuneiform, suggesting a high degree of hallucial abduction (Fig. 1). Gomberg (1981) observed that the degree of medial tilt is approximately the same in chimpanzees and western gorillas but intermediate between orangutans and modern humans. Groves (2001) also used hallux orientation as part of his taxonomic diagnoses of eastern gorillas, describing mountain gorillas as having a more adducted hallux and grauer gorillas a more divergent one.

In this study, we test the hypothesis that medial cuneiform morphology falls on a morphocline that tracks hallucial abduction ability and arboreality in gorillas. Although gorillas are closely related to each other and they share a fundamental locomotor strategy of knuckle-walking, taxa differ in terms of their dietary strategies and their frequency of arboreality (Tuttle, 1970; Tuttle and Watts, 1985; Langdon, 1986; Hunt, 1991, 1992; Remis, 1994, 1998; Ruvolo et al., 
1994; Sarmiento, 1994; Garner and Ryder, 1996; Ruvolo, 1997; Saltonstall et al., 1998; Gagneux et al., 1999; Clifford et al., 2003; Jensen-Seaman et al., 2003; Taylor and Goldsmith, 2003; Thalmann et al., 2005, 2007; Anthony et al., 2007). This gradient predicts that mountain gorillas should display a medial cuneiform anatomy with the least hallucial abduction ability, followed by grauer gorillas, and then by western gorillas. Previous work has also suggested that medial cuneiform anatomy will vary according to these predictions (Schultz, 1930,1934; Gomberg, 1981; Sarmiento, 1994), but this study represents the first time that this anatomy has been analyzed in three dimensions (Fig. 2). Of course, such functional and behavioral predictions can be complicated by phylogenetic relationships; thus, we first test whether the more closely-related eastern gorilla taxa differ from that of western gorillas along our predicted morphocline (Ruvolo et al., 1994; Garner and Ryder, 1996; Ruvolo, 1997; Groves, 2001, 2003; Jensen-Seaman et al., 2003; Oates et al., 2003;
Thalmann et al., 2005, 2007; Anthony et al., 2007). Subsequently, we examine whether mountain and grauer gorillas differ from each other in a similar fashion.

An ecomorphological study of gorillas may provide insight into how well morphology can be 'fine-tuned' in its adaptation to a particular habitus. For example, a greater degree of observed humeral torsion in mountain gorillas may suggest a more terrestrial adaptation relative to their western counterparts, while other features of the forelimb appear less informative in this regard (Inouye, 2003). Recent work examining African ape hand and foot morphology in relation to frequencies of arboreality and terrestriality did not find strong, if any, concordance between functional predictions and the observed morphology (Jabbour, 2008). These findings underscore both the difficulty and critical importance of identifying skeletal features that have a clear functional and adaptive meaning. As Jabbour (2008: 516) states, "If a clear relationship could

Table 2

Results of three error analyses (Method, Threshold, and Observer) using a repeated measures ANOVA design (see Fig. 3 for variable acronyms)

\begin{tabular}{|c|c|c|c|c|c|c|c|c|c|c|c|c|c|c|c|}
\hline & & & \multicolumn{6}{|c|}{ Angles } & \multicolumn{5}{|c|}{ Relative Areas } & \multicolumn{2}{|c|}{ Curvatures $^{1}$} \\
\hline & & & cun2-mt1 & cun2-mt2 & cun2-nav & $\mathrm{mt} 1-\mathrm{mt} 2$ & mt1-nav & mt2-nav & cun2 & $\mathrm{mt} 1$ & $\mathrm{mt} 2$ & nart & nav & $\mathrm{mt} 1-\mathrm{A}$ & $\mathrm{mt} 1-\mathrm{B}$ \\
\hline \multirow{5}{*}{$\begin{array}{l}\text { Dृ } \\
\text { 坖 } \\
\sum\end{array}$} & M1 & CT & 30 & 150 & 123 & 60 & 28 & 93 & 4.2 & 16.6 & 2.4 & 67.0 & 9.9 & -0.03 & -1.71 \\
\hline & M2 & Laser & 31 & 149 & 124 & 61 & 27 & 93 & 4.3 & 16.9 & 2.3 & 66.8 & 9.8 & -0.05 & -1.69 \\
\hline & & $\mathrm{F}$ & 0.69 & 0.88 & 0.50 & 0.45 & 0.35 & 0.19 & 0.81 & 0.38 & 0.48 & 0.55 & 0.96 & 0.11 & 0.70 \\
\hline & $\frac{\vec{J}}{>}$ & Normality & $>0.1$ & $>0.1$ & $>0.1$ & $>0.1$ & $>0.1$ & $>0.1$ & $>0.1$ & $>0.1$ & $>0.1$ & $>0.1$ & $>0.1$ & $>0.1$ & $>0.1$ \\
\hline & & Variance & 0.59 & 0.81 & 0.83 & 0.87 & 0.85 & 0.90 & 0.23 & 0.92 & 0.45 & 0.99 & 0.78 & 0.90 & 0.70 \\
\hline \multirow{7}{*}{ 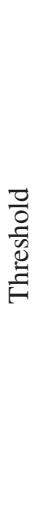 } & $\mathrm{T} 1$ & $\mathrm{x} \mathrm{HU}^{2}$ & 29 & 149 & 123 & 60 & 29 & 93 & 4.2 & 16.2 & 2.3 & 67.3 & 10.0 & -0.03 & -1.68 \\
\hline & $\mathrm{T} 2$ & $\mathrm{x}-100 \mathrm{HU}$ & 30 & 150 & 123 & 60 & 28 & 93 & 4.1 & 16.6 & 2.4 & 66.9 & 10.0 & -0.03 & -1.73 \\
\hline & $\mathrm{T} 3$ & $\mathrm{x}-200 \mathrm{HU}$ & 30 & 149 & 123 & 61 & 28 & 92 & 4.3 & 16.4 & 2.4 & 67.0 & 9.9 & -0.03 & -1.69 \\
\hline & $\mathrm{T} 4$ & $\mathrm{x}-300 \mathrm{HU}$ & 30 & 149 & 123 & 61 & 28 & 92 & 4.4 & 16.6 & 2.5 & 66.4 & 10.1 & -0.04 & -1.72 \\
\hline & & $\mathrm{F}$ & 0.70 & 0.16 & 0.62 & 0.27 & 0.73 & 0.34 & 0.03 & 0.07 & 0.03 & 0.05 & 0.74 & 0.32 & 0.10 \\
\hline & $\frac{\sqrt[3]{\pi}}{>}$ & Normality & $>0.1$ & $>0.1$ & $>0.1$ & $>0.1$ & $>0.1$ & $>0.1$ & $>0.1$ & $>0.1$ & 0.07 & $>0.1$ & $>0.1$ & $>0.1$ & $>0.1$ \\
\hline & & Variance & 0.95 & 1.00 & 1.00 & 1.00 & 0.93 & 0.99 & 0.91 & 0.98 & 0.93 & 0.93 & 1.00 & 1.00 & 1.00 \\
\hline \multirow{5}{*}{$\begin{array}{l}\dot{0} \\
\sum_{0}^{0} \\
0 \\
0 \\
0\end{array}$} & $\mathrm{O} 1$ & MWT & 30 & 150 & 123 & 60 & 28 & 93 & 4.2 & 16.6 & 2.4 & 67.0 & 9.9 & -0.03 & -1.71 \\
\hline & $\mathrm{O} 2$ & CRS & 31 & 147 & 125 & 63 & 25 & 93 & 4.3 & 16.4 & 2.4 & 67.5 & 9.4 & -0.03 & -1.59 \\
\hline & & $\mathrm{F}$ & 0.47 & 0.13 & 0.14 & 0.17 & 0.15 & 0.90 & 0.68 & 0.85 & 0.97 & 0.66 & 0.36 & 0.86 & 0.01 \\
\hline & $\frac{\sqrt{3}}{3}$ & Normality & $>0.1$ & $>0.1$ & $>0.1$ & $>0.1$ & $>0.1$ & $>0.1$ & $>0.1$ & $>0.1$ & $>0.1$ & $>0.1$ & $>0.1$ & $>0.1$ & $>0.1$ \\
\hline & & Variance & 0.93 & 0.69 & 0.71 & 0.97 & 0.20 & 0.96 & 0.32 & 0.98 & 0.56 & 0.92 & 0.29 & 0.98 & 0.83 \\
\hline
\end{tabular}

\footnotetext{
${ }^{1} \mathrm{mt1}$-A, dorsoplantar curvature; mt1-B, mediolateral curvature (see text for details).
}

${ }^{2}$ HU, Hounsfield units 
be found between variation in modern African ape morphology and variation in modern African ape habitats and positional behavior, it would provide a powerful tool for the ecological interpretation of morphological variation in fossil hominoids."

Three-dimensional (3D) approaches to studying hand and foot anatomy provide advantages over linear approaches in that they can provide quantitative metrics in some instances that better capture functionally meaningful shape differences. For example, recent 3D analyses of carpal variation among living and fossil hominids provided compelling evidence of functionally significant, derived wrist anatomy in modern humans and Neandertals relative to extant great apes and other hominins (Tocheri et al., 2003, 2005, 2007, 2008; Tocheri, 2007, 2009; Marzke et al., 2010). In this study, we quantify features that contribute to hallucial abduction and have designed a similar 3D approach. For instance, we expect that angles involving the first metatarsal facet should differ in predictable ways that demonstrate that the hallux is oriented in a more or less abducted position, following the original observations of Schultz (1930, 1934) (Fig. 1). In comparison with eastern gorillas, the first metatarsal facet in western gorillas should show: 1) an angle with the second metatarsal facet that is more acute (Fig. 1c and $\mathrm{d}-\mathrm{E}-\mathrm{F}), 2$ ) an angle with the second cuneiform facet that is more parallel (Fig. 1d-E-G), and 3) an angle with the navicular facet that is less parallel (Fig. 1d-E-H). Together, these angles indicate that the hallux is set in a more abducted position relative to the rest of the foot. We also expect that western gorillas should exhibit an articular area for the first metatarsal that is proportionately larger (relative to the entire surface area of the medial cuneiform) (Fig. 2) and more curved mediolaterally (Fig. 1e) than in eastern gorillas, again following Schultz $(1930,1934)$. These variables indicate more potential to utilize the abducted hallux in a variety of positions when grasping variably sized arboreal supports.

\section{Materials and methods}

\section{Samples}

Fifty-four medial cuneiforms from 40 gorilla specimens (13 mountain, 13 grauer, and 14 western gorillas) compose the selected study sample (Table 1 ). For the 14 individuals where both left and right bones were included, the right side was used only as a testing sample in the multivariate analyses (see below). These 40 gorillas derive from museum collections at the United States National Museum of Natural History (USNM), the Academy of Natural Sciences in Philadelphia (ANSP), and the Royal Museum for Central Africa in Belgium (RMCA).

\section{Data acquisition}

All medial cuneiforms were either laser or CT scanned to generate 3D models for further analysis. CT scanning was performed using a SIEMENS Somatom Emotion CT scanner (110 kV,
$70 \mathrm{~mA}, 1 \mathrm{~mm}$ slice thickness, $0.1 \mathrm{~mm}$ reconstruction increment, H50 moderately sharp kernel). Slices were loaded into Materialise Mimics software and surface models were generated using four evenly dispersed threshold values spanning 300 Hounsfield Units (HU) (e.g., -200 HU, -100 HU, $0 \mathrm{HU}$, and $100 \mathrm{HU}$ ). The surface model that visually appeared to best capture the bone surface was selected for further processing. Laser scanning was performed using a NextEngine 3D Scanner HD (macro setting, 16 scans per orientation, and minimum two orientations per bone). Each set of 16 scans was aligned and merged using ScanStudioHD software and exported as a triangular mesh. The resulting meshes for each bone were then aligned and merged using Geomagic Studio software. All resulting surface models were then digitally cleaned to remove unnecessary data (e.g., internal bone surface) and correct any imperfections in the triangular mesh structure (e.g., hole-filling, removal of overlapping triangles, etc).

The 3D medial cuneiform models were digitally segmented using Geomagic Studio software into articular and nonarticular areas by two of us (MWT and CRS), while visually referring to the actual bone. Three metrics of interest were quantified: angles between articular surfaces, relative areas of articular and nonarticular surfaces, and curvatures of the hallucial articular surface. All of these metrics represent scale-free variables that describe particular aspects of medial cuneiform shape (Mosimann, 1970; Falsetti et al., 1993; Jungers et al., 1995). Angles between articular surfaces were calculated as the angles between least-squares planes fitted to each articular area (Figs. 1d and 3). Relative areas represent the proportion that each surface occupies on the entire surface area of the medial cuneiform (e.g., hallucial articular surface area/total bone surface area) (Figs. 2 and $3 \mathrm{~A}-\mathrm{E}$ ). Curvatures were measured in two orthogonal directions (i.e., dorsoplantar and mediolateral) by fitting a quadric surface to each hallucial facet (Figs. $1 \mathrm{f}$ and $3 \mathrm{~F}$ ). The algorithmic methods for quantifying these metrics have been detailed elsewhere and are not repeated here (Tocheri et al., 2003, 2005, 2007; Tocheri, 2007, 2009; Marzke et al., 2010).

\section{Error analyses}

To ensure the method of data acquisition (CT vs laser scanning), threshold values of the CT scans (4 levels), or observer (MWT vs CRS) did not have significant effects on the comparative analyses, three error analyses were conducted using a repeated measures ANOVA design. Five medial cuneiforms were selected at random, using a sample-without-replacement procedure from the gorillas in the USNM sample, and each was CT and laser scanned. Four surface models were generated from the CT scans, using four evenly dispersed threshold values spanning $300 \mathrm{HU}$ that visually appeared to best capture the bone surface. The four resulting surface models, along with the surface model generated directly from the laser scans, were then digitally cleaned and segmented into articular and nonarticular areas by MWT, and one of the four CT models was also selected independently and segmented by CRS. The resulting

Table 3

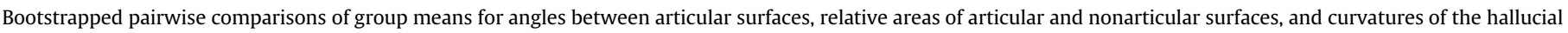
surface (see Fig. 3 and Table 2 for variable acronyms).

\begin{tabular}{|c|c|c|c|c|c|c|c|c|c|c|c|c|c|c|}
\hline \multirow[b]{2}{*}{ Taxon } & \multirow[b]{2}{*}{$\mathrm{N}$} & \multicolumn{6}{|c|}{ Angles } & \multicolumn{5}{|c|}{ Relative Areas } & \multicolumn{2}{|c|}{ Curvatures } \\
\hline & & cun2-mt1 & cun2-mt2 & cun2-nav & $\mathrm{mt} 1-\mathrm{mt} 2$ & mt1-nav & mt2-nav & cun2 & $\mathrm{mt} 1$ & $\mathrm{mt2}$ & nav & nart & $\mathrm{mt} 1-\mathrm{A}$ & $m t 1-B$ \\
\hline G. g. gorilla & 14 & 32 & $156^{\mathrm{B}, \mathrm{C}}$ & $118^{\mathrm{B}, \mathrm{C}}$ & $55^{\mathrm{B}, \mathrm{C}}$ & $31^{\mathrm{C}}$ & $95^{\mathrm{B}}$ & 4.6 & 17.8 & $2.6^{\mathrm{C}}$ & $10.1^{\mathrm{B}}$ & $64.9^{\mathrm{B}, \mathrm{C}}$ & 0.0 & $-2.0^{\mathrm{B}, \mathrm{C}}$ \\
\hline Western gorillas & 14 & 32 & $156^{\mathrm{E}}$ & $118^{\mathrm{E}}$ & $55^{\mathrm{E}}$ & $31^{\mathrm{E}}$ & 95 & 4.6 & 17.8 & $2.6^{\mathrm{E}}$ & 10.1 & $64.9^{\mathrm{E}}$ & 0.0 & $-2.0^{\mathrm{E}}$ \\
\hline G. b. beringei & 13 & 27 & $137^{\mathrm{A}}$ & $128^{\mathrm{A}, \mathrm{C}}$ & $69^{\mathrm{A}}$ & $26^{\mathrm{C}}$ & $86^{\mathrm{A}, \mathrm{C}}$ & 4.5 & 16.4 & $2.4^{\mathrm{C}}$ & $9.0^{\mathrm{A}, \mathrm{C}}$ & $67.8^{\mathrm{A}}$ & -0.1 & $-1.6^{\mathrm{A}}$ \\
\hline G. b. graueri & 13 & 27 & $140^{\mathrm{A}}$ & $135^{\mathrm{A}, \mathrm{B}}$ & $65^{\mathrm{A}}$ & $19^{\mathrm{A}, \mathrm{B}}$ & $96^{\mathrm{B}}$ & 4.0 & 16.9 & $1.7^{\mathrm{A}, \mathrm{B}}$ & $10.0^{\mathrm{B}}$ & $67.5^{\mathrm{A}}$ & -0.1 & $-1.6^{\mathrm{A}}$ \\
\hline Eastern gorillas & 26 & 27 & $138^{\mathrm{W}}$ & $131^{\mathrm{W}}$ & $67^{\mathrm{W}}$ & $23^{\mathrm{W}}$ & 91 & 4.2 & 16.6 & $2.1^{\mathrm{W}}$ & 9.5 & $67.6^{\mathrm{W}}$ & -0.1 & $-1.6^{\mathrm{W}}$ \\
\hline
\end{tabular}

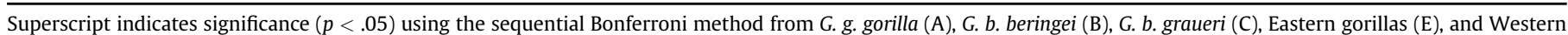
gorillas (W). 
Table 4

Posterior probabilities of group membership among eastern and western gorillas using six angles, four relative areas, and two curvatures (correct classifications emphasized in bold face).

\begin{tabular}{|c|c|c|c|c|c|}
\hline & \multicolumn{2}{|c|}{ Classification Sample } & & \multicolumn{2}{|c|}{ Testing Sample } \\
\hline & Eastern & Western & & Eastern & Western \\
\hline Eastern & 24 & 2 & Eastern & 4 & 0 \\
\hline$\%$ & 92.3 & 7.7 & $\%$ & 100.0 & 0.0 \\
\hline Western & 1 & 13 & Western & 0 & 10 \\
\hline$\%$ & 7.1 & 92.9 & $\%$ & 0.0 & 100.0 \\
\hline
\end{tabular}

angular, relative area, and curvature data from these five gorillas were used for the three repeated measures ANOVA error analyses. Statistical significance was evaluated for each error analysis using an alpha value of 0.05 and the sequential Bonferroni correction (Holm, 1979; Rice, 1989).

\section{Statistical analyses}

Differences between gorilla taxa for the means of each measured variable were evaluated for statistical significance using a standard resampling method (i.e., bootstrapping) ideally suited to examine differences between means of groups with varying sample sizes that are small relative to the population they represent (Efron and Tibshirani, 1993; Manly, 1997). One thousand means for each variable and taxon were generated after sampling with replacement from each original sample. For each pairwise comparison, the 1000 means from taxon A were randomly aligned with the 1000 means from taxon $B$ and 1000 differences between the two means were calculated. These differences were then compared with the difference between the means of the original samples. The number of times the difference between the bootstrapped means exceeded the difference between the original sample means represents the $p$ value of a one-tailed test (e.g., $1 / 1000$ equals $p=0.001$ ), whereas the number of times the absolute difference between the bootstrapped means exceeded the absolute difference between the original sample means represents the $p$ value of a two-tailed test (i.e., non-directional). When there was no a priori reason for expecting any directionality in the differences between means, a two-tailed test was used; otherwise, the a priori expected direction of difference was used and a one-tailed test was performed (e.g., western gorillas should show a more mediolaterally curved hallucial facet than mountain gorillas). The bootstrap results ensure that statements about the means can be made with statistical

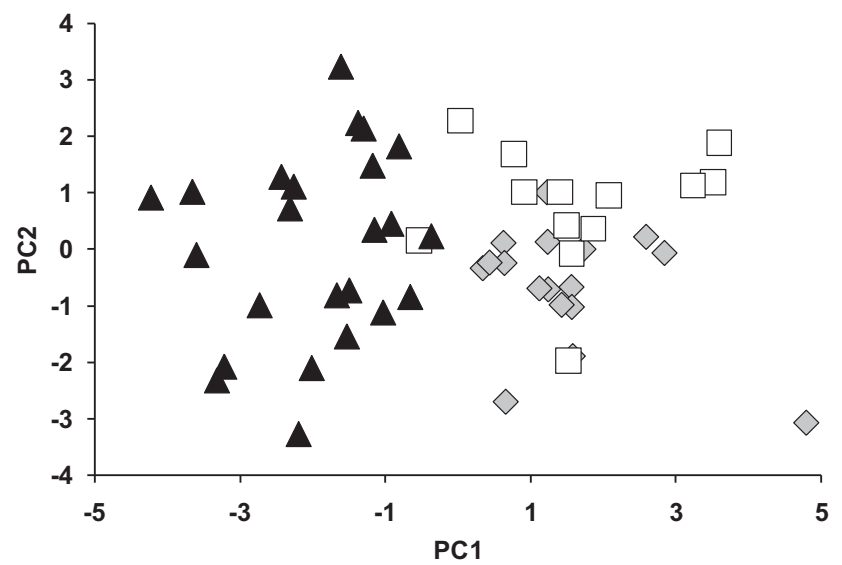

Figure 5. Plot of first (PC1) and second (PC2) principal components that explains $36 \%$ of the variance among gorilla taxa and illustrates the divergence between eastern and western gorillas (western, closed triangles; mountain, grey diamonds; grauer, open squares).

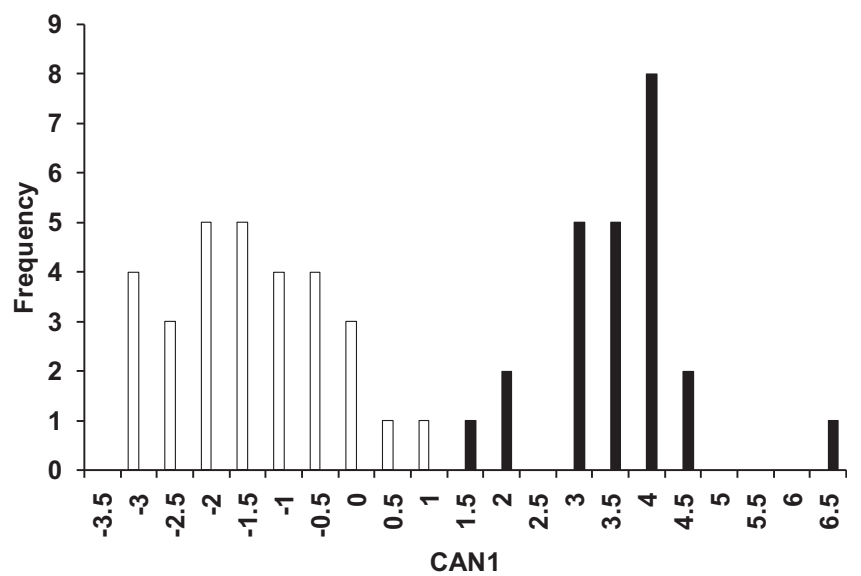

Figure 6. Histogram of canonical scores that explains $100 \%$ of the variance among eastern (open bars) and western gorillas (closed bars).

confidence. For all pairwise comparisons, an alpha value of 0.05 was adjusted using the sequential Bonferroni correction method and used to determine statistical significance (Holm, 1979; Rice, 1989).

Principal components analysis (PCA) and canonical variates analysis (CVA) were used to reduce, ordinate, and graphically interpret the observed multivariate variation, while the posterior probabilities of Gorilla group membership were calculated using discriminant analysis (DA). For the PCA, the correlation matrix was used as the starting point of the analysis because our variables include various units of measurement. For the DA and CVA, the starting point of the analyses used the pooled within-class covariance matrix, which results in linear as opposed to quadratic discriminant functions. CVA and DA are interrelated and reduce the data into $N-1$ variables that explain $100 \%$ of the variance, where $N$ is equal to the number of specified groups (Johnson and Wichern, 2002). PCA differs in that it does not incorporate any information about group membership and thus reduces the data into $N$ components explaining $100 \%$ of the variance, where $N$ equals the number of variables used in the analysis (Johnson and Wichern, 2002). Each resulting canonical variable and principal component represents a linear combination of the six angles, four relative areas, and two curvatures used in each analysis (note that since all five relative areas sum to 1.0 , the relative nonarticular area is excluded from the multivariate analyses as it is implied by the remaining four and would otherwise result in matrix singularity). To determine which angles, areas, and curvatures contribute significantly to the variation observed within each canonical variable and principal component, we used the pooled within-group canonical structure for the CVA and the correlations of each variable with each component for the PCA, respectively.

The posterior probabilities of the DA represent the likelihood of correctly assigning each medial cuneiform to its respective gorilla taxon using the selected 3D shape variables. We used cross-validated (jack-knifed) posterior probabilities because they are

Table 5

Posterior probabilities of group membership among mountain and grauer gorillas using six angles, four relative areas, and two curvatures (correct classifications emphasized in bold face)

\begin{tabular}{cccccc}
\hline & \multicolumn{2}{c}{ Classification Sample } & & \multicolumn{2}{c}{ Testing Sample } \\
\cline { 2 - 4 } & Mountain & Grauer & & Mountain & Grauer \\
\hline Mountain & $\mathbf{1 1}$ & 2 & Mountain & $\mathbf{4}$ & 0 \\
$\%$ & $\mathbf{8 4 . 6}$ & 15.4 & $\%$ & $\mathbf{1 0 0 . 0}$ & 0.0 \\
Grauer & 1 & $\mathbf{1 2}$ & Grauer & 0 & $\mathbf{0}$ \\
$\%$ & 7.7 & $\mathbf{9 2 . 3}$ & $\%$ & 0.0 & $\mathbf{0 . 0}$ \\
\hline
\end{tabular}




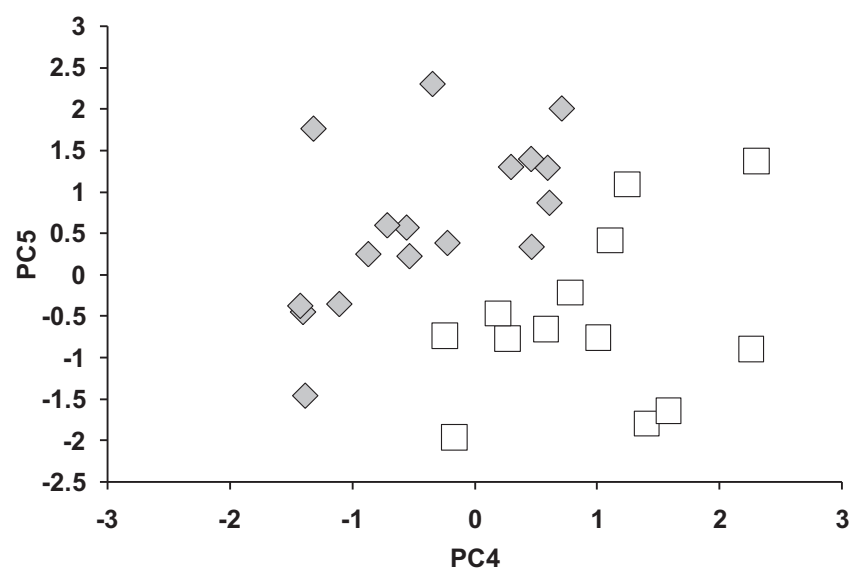

Figure 7. Plot of fourth (PC4) and fifth (PC5) principal components that explains $17 \%$ of the variance among gorilla taxa (western, not shown; mountain, grey diamonds; grauer, open squares) and shows the separation of mountain and grauer gorillas similar to that observed in the CVAs. Note that the third (PC3) principal component is not illustrated as it does not contribute any additional meaningful separation that is not already shown in PCs 1, 2, 4, and 5.

calculated for each specimen after excluding it from the classification sample, and as such give approximately unbiased estimates of the probabilities of misclassification (Johnson and Wichern, 2002). The extra right medial cuneiforms of 14 gorillas in the sample were used only as an a posteriori testing sample in the DA and CVA to examine how well they could be classified given the data derived from their antimeres and the additional samples.

All statistical analyses were conducted using SAS/STAT software, Version 9.1 of the SAS System for Microsoft ${ }^{\circledR}$ Windows (SAS Institute, 2002), except for the PCA, which was performed using PAST (Hammer and Harper, 2006). The box-and-whisker plots shown in Figs. 3 and 4 were generated using STATISTICA, Version 9 (StatSoft, 2010).

\section{Results}

Error analyses

The three error analyses detected no statistically significant effects due to data acquisition method (CT vs laser scan), threshold value (four levels), or observer (MWT vs CRS) for the 13 scale-free shape metrics used in this study (Table 2). None of the 39 comparisons were significant using the sequential Bonferroni

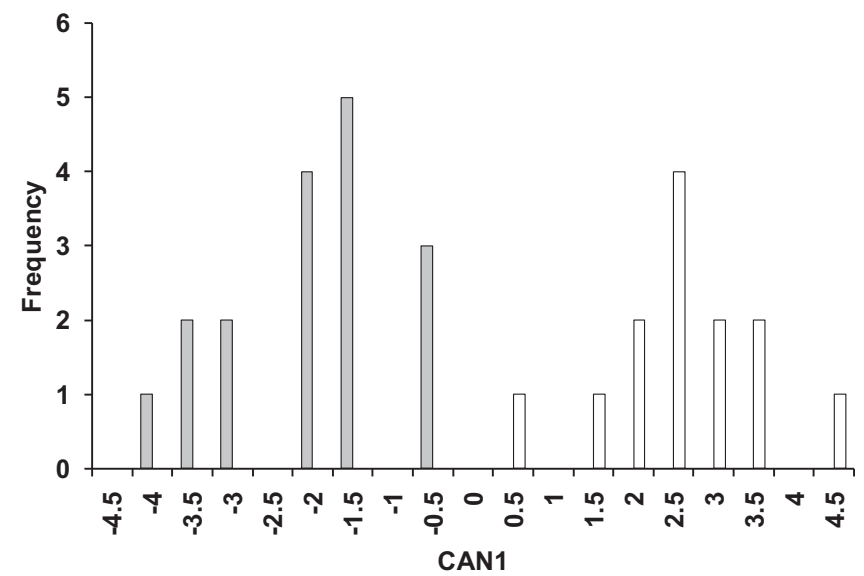

Figure 8. Histogram of canonical scores that explains $100 \%$ of the variance among mountain (grey bars) and grauer gorillas (open bars).

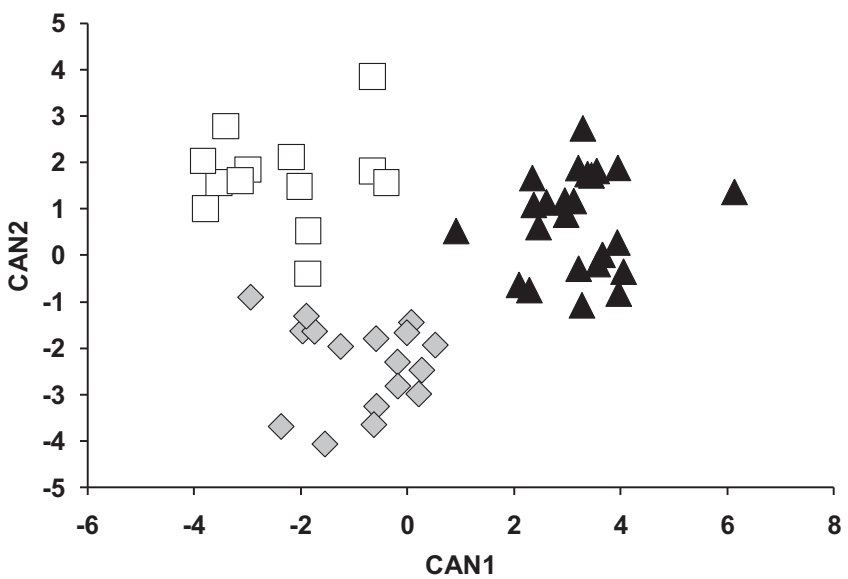

Figure 9. Plot of first (CAN1) and second (CAN2) canonical variables that explains $100 \%$ of the variance among gorilla taxa and illustrates the divergence between western (closed triangles), mountain (grey diamonds), and grauer gorillas (open squares).

adjustment. Three of these were significant prior to the adjustment but all show mean differences or effects that are small compared with those observed between taxa. These results indicate that the metrics employed in this study are reasonably independent of data acquisition method, threshold value, and observer, and provide ample justification for pooling data collected using either CT or laser scans, any of the four thresholds, and from the two observers (MWT and CRS).

\section{Eastern vs western gorillas}

The bootstrap and multivariate results demonstrate that medial cuneiform shape in eastern gorillas is easily distinguishable from that in western gorillas (Tables 3 and 4, Figs. 3 and 4). Plots of both the PCA and CVA reveal clearly defined clusters (Figs. 5 and 6 ) and the DA successfully classifies $92 \%$ of eastern gorillas and $93 \%$ of western gorillas using the cross-validated classification sample, and $100 \%$ of each using the testing sample (Table 4 ). With respect to our functional predictions, the angle between the first and second metatarsal facets is more acute in western gorillas than in eastern gorillas ( $55^{\circ}$ vs $67^{\circ}, p<0.001$; Fig. 3D), and the angle between the first metatarsal and navicular facets is less parallel in the former than in the latter $\left(31^{\circ}\right.$ vs $22^{\circ}, p=0.001$; Fig. $\left.3 \mathrm{E}\right)$. Both of these angles indicate a more medially oriented hallucial facet in western gorillas. Western gorillas also exhibit a first metatarsal surface area that is proportionately larger ( $17.8 \%$ vs $16.6 \%, p=0.021$; Fig. $4 \mathrm{~B}$ ) and more curved mediolaterally ( -2.0 vs $-1.6, p<0.001$; Fig. $4 \mathrm{~F}$ ) than in eastern gorillas. All of these variables contribute significantly to the separation observed in the PCA and CVA plots (Table 7). The one prediction that does not hold is the result for the angle between the first metatarsal and second cuneiform facets. Rather than this angle appearing more parallel in western gorillas, the opposite is observed $\left(32^{\circ}\right.$ in western vs $27^{\circ}$ in eastern gorillas, $p=0.015^{3}$; Fig. $3 \mathrm{~A}$ ), although this variable does not contribute as significantly to the separation observed in Figs. 5 and 6.

Two angles that were not part of our functional predictions show the strongest loadings along CAN1 and PC1 (Table 7). These are the angles between the second cuneiform facet and both the second metatarsal and navicular facets ( $p<0.001$ for both; Fig. 3B and C).

\footnotetext{
${ }^{3}$ Note that this $p$ value is the result of a two-tailed test because the direction of difference was opposite to what was expected.
} 
Table 6

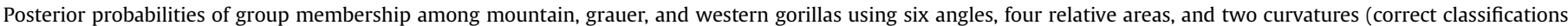
emphasized in bold face).

\begin{tabular}{|c|c|c|c|c|c|c|c|}
\hline & \multicolumn{3}{|c|}{ Classification Sample } & & \multicolumn{3}{|c|}{ Testing Sample } \\
\hline & Mountain & Grauer & Western & & Mountain & Grauer & Western \\
\hline Mountain & 11 & 2 & 0 & Mountain & 4 & 0 & 0 \\
\hline$\%$ & 84.6 & 15.4 & 0.0 & $\%$ & 100.0 & 0.0 & 0.0 \\
\hline Grauer & 1 & 12 & 0 & Grauer & 0 & $\mathbf{0}$ & 0 \\
\hline$\%$ & 7.7 & 92.3 & 0.0 & $\%$ & 0.0 & 0.0 & 0.0 \\
\hline Western & 2 & 0 & 12 & Western & 0 & 0 & 10 \\
\hline$\%$ & 14.3 & 0.0 & 85.7 & $\%$ & 0.0 & 0.0 & 100.0 \\
\hline
\end{tabular}

These angles are more similar to one another in eastern gorillas $\left(138^{\circ}\right.$ and $\left.131^{\circ}\right)$ than they are in western gorillas $\left(156^{\circ}\right.$ and $\left.118^{\circ}\right)$.

\section{Grauer vs mountain gorillas}

The statistical results demonstrate that medial cuneiform shape is also distinguishable between the two eastern gorilla subspecies (Tables 3 and 5, Figs. 3 and 4), but slightly less so in comparison with the differences between western and eastern gorillas. Plots of both the PCA and CVA reveal clearly defined clusters (Figs. 7 and 8) and the DA successfully classifies $85 \%$ of mountain gorillas and $92 \%$ of grauer gorillas using the cross-validated classification sample, and $100 \%$ of mountain gorillas using the testing sample (Table 5). However, the variables that contribute the most to separating eastern gorilla subspecies from each other do not follow our functional predictions (Tables 3 and 7). For example, the three angles involving the navicular facet (Fig. 3C, E, F) and the relative areas of the second metatarsal and navicular facets (Fig. 4C, D) are the driving force behind the separation of these two taxa. Thus, the distinguishing characteristics of these two taxa appear largely unrelated to differences in hallucial abduction ability and frequency of arboreality.

\section{All three gorilla taxa compared}

Overall, the same results are obtained when all three gorilla taxa are included in the multivariate analyses. The CVA reveals three clearly defined clusters (Fig. 9; see Figs. 5 and 7 for the PCA) and the DA successfully classifies $85 \%$ of mountain gorillas, $92 \%$ of grauer gorillas, and $86 \%$ of western gorillas using the cross-validated classification sample, and $100 \%$ of mountain and western gorillas using the testing sample (Table 6). The variables that contribute to the observed clustering and separation along the first canonical axis are the same as those reported for the CVA of eastern and western gorillas, and those that contribute to the observed clustering and separation along the second canonical axis are the same as those reported for the CVA of mountain and grauer gorillas (Table 7).

As a further test of our functional hypothesis, we performed an additional CVA that only included the five variables we predicted a priori to be associated with hallucial abduction ability. In addition to our testing sample of 14 gorillas, we used 22 bonobos (Pan paniscus; all from RMCA) and 19 chimpanzees (Pan troglodytes; from USNM and ANSP) to further examine whether these five variables are functionally related to a more prehensile, abducted hallux. Note that Pan is only used here as a testing sample and does not contribute to the observed distribution of gorillas in this CVA. Again, three clearly defined clusters are observed with eastern gorillas clearly separated from western gorillas along the first canonical axis (Fig. 10) and all five variables contribute to the observed clustering and separation in a similar way as the previous analyses (Table 7). The DA successfully classifies $77 \%$ of mountain gorillas, $85 \%$ of grauer gorillas, and $79 \%$ of western gorillas using the cross-validated classification sample, and $75 \%$ of mountain and $90 \%$ of western gorillas using the testing sample (Table 8 ). Importantly, $73 \%$ of bonobos and $74 \%$ of chimpanzees are classified as western gorillas (Table 8) and each of these individuals plots within the distributed range of western gorillas along the first canonical axis (Fig. 10). Together, these results provide additional support that eastern gorillas differ from western gorillas, chimpanzees, and bonobos due

Table 7

Correlations between each medial cuneiform variable and multivariate axis ${ }^{\mathrm{a}}$ for the analyses presented and figured herein. ${ }^{\mathrm{b}}$

\begin{tabular}{|c|c|c|c|c|c|c|c|c|c|c|c|}
\hline \multirow{2}{*}{\multicolumn{2}{|c|}{$\frac{\text { Variable }}{\text { Angle between }}$}} & \multirow{3}{*}{$\frac{\frac{\text { E vs W }}{\text { CAN1 }}}{0.17}$} & \multirow{3}{*}{$\frac{\frac{\mathrm{M} \text { vs G }}{\text { CAN1 }}}{0.00}$} & \multicolumn{2}{|c|}{ All three taxa } & \multicolumn{2}{|c|}{ All three taxa ${ }^{c}$} & \multicolumn{4}{|c|}{ All three taxa } \\
\hline & & & & \multirow{2}{*}{$\frac{\text { CAN1 }}{0.16}$} & \multirow{2}{*}{$\frac{\text { CAN2 }}{0.06}$} & \multirow{2}{*}{$\begin{array}{c}\text { CAN1 } \\
\mathbf{0 . 2 7}\end{array}$} & \multirow{2}{*}{$\frac{\text { CAN2 }}{-0.06}$} & \multirow{2}{*}{$\begin{array}{c}\text { PC1 } \\
-0.38\end{array}$} & \multirow{2}{*}{$\frac{\text { PC2 }}{0.21}$} & \multirow{2}{*}{$\frac{\text { PC4 }}{0.15}$} & \multirow{2}{*}{$\begin{array}{l}\text { PC5 } \\
\mathbf{0 . 3 4}\end{array}$} \\
\hline 2nd cuneiform & 1st metatarsal & & & & & & & & & & \\
\hline 2nd cuneiform & 2nd metatarsal & 0.47 & 0.08 & 0.43 & 0.25 & & & -0.89 & 0.38 & 0.04 & 0.06 \\
\hline 2nd cuneiform & navicular & -0.42 & 0.26 & -0.49 & 0.10 & & & 0.85 & 0.22 & 0.06 & -0.19 \\
\hline 1st metatarsal & 2nd metatarsal & -0.36 & -0.15 & -0.32 & -0.26 & -0.57 & 0.41 & 0.79 & -0.34 & 0.00 & 0.17 \\
\hline 1st metatarsal & navicular & 0.27 & -0.26 & 0.33 & -0.16 & 0.53 & 0.41 & -0.73 & -0.44 & -0.21 & -0.10 \\
\hline 2nd metatarsal & navicular & 0.11 & 0.47 & 0.05 & 0.41 & & & -0.31 & 0.84 & 0.20 & -0.13 \\
\hline \multicolumn{12}{|c|}{ Relative surface area } \\
\hline 2nd & form & 0.09 & -0.12 & 0.11 & -0.09 & & & -0.23 & -0.79 & 0.08 & -0.24 \\
\hline 1 st $\mathrm{r}$ & arsal & 0.15 & 0.07 & 0.13 & 0.12 & 0.23 & -0.20 & -0.64 & -0.15 & 0.32 & -0.12 \\
\hline 2nd & arsal & 0.20 & -0.39 & 0.28 & -0.24 & & & -0.42 & 0.10 & -0.66 & 0.43 \\
\hline & & 0.14 & 0.24 & 0.10 & 0.32 & & & -0.43 & 0.05 & 0.15 & -0.40 \\
\hline \multicolumn{12}{|c|}{ Curvature } \\
\hline Dor: & ntar & 0.16 & 0.04 & 0.15 & 0.09 & & & -0.10 & 0.20 & -0.58 & -0.61 \\
\hline Mec & eral & -0.30 & -0.03 & -0.27 & -0.13 & -0.47 & 0.17 & 0.78 & 0.30 & -0.12 & -0.12 \\
\hline
\end{tabular}

\footnotetext{
a Canonical axes, CAN\#; prinicipal component axes, PC\#; best explanatory variables emphasized in bold face.

b Eastern (E) vs Western (W) gorillas; Mountain (M) vs Grauer (G) gorillas; All three taxa (Western, Mountain, and Grauer gorillas).

c Uses only the five variables predicted a priori to be associated with hallucial abduction ability, and includes chimpanzees and bonobos as an a posteriori testing sample (see Fig. 10).
} 


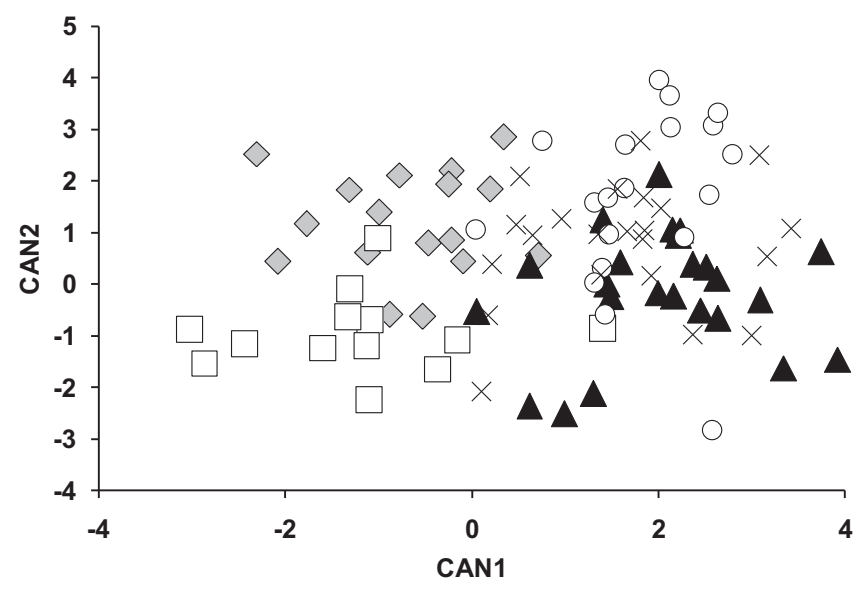

Figure 10. Plot of first (CAN1) and second (CAN2) canonical variables that explains $100 \%$ of the variance among gorilla taxa using only the five variables predicted a priori to be associated with hallucial abduction ability (see text for details). Note the observed divergence between western (closed triangles), mountain (grey diamonds), and grauer gorillas (open squares). Chimpanzees (open circles) and bonobos (Xs), used here only as an a posteriori testing sample, differ from eastern gorillas in ways similar to western gorillas (see text for details).

to morphological differences that are related to decreased hallucial abduction ability and lower frequencies of arboreality.

\section{Discussion}

As Schultz $(1930,1934)$ first observed, the feet of western gorillas are quite distinct from those of eastern gorillas, and several studies have continued to echo this observation (Gomberg, 1981; Moriyama, 1985; Sarmiento, 1994; Sarmiento and Marcus, 2000; Harcourt-Smith, 2002; Jabbour, 2008). In terms of hallucial abduction, based on a limited sample, Schultz (1930) noted that the angle of abduction was less in eastern $(\mathrm{N}=2)$ than in western gorillas $(\mathrm{N}=4)$, which instead exhibited an abduction angle more similar to chimpanzees (Fig. 1c). He also observed a less convex and more distally oriented hallucial tarsometatarsal joint in mountain gorillas (i.e., more adducted). Our quantitative 3D analyses of the gorilla medial cuneiform confirm and extend Schultz's original observations in several important ways (Figs. 1-10), particularly in relation to the growing wealth of information on gorilla morphology and behavior within specific ecological habitats (Groves, 1970, 1971, 2003; Tuttle, 1970; Tuttle and Watts, 1985; Langdon, 1986; Hunt, 1991, 1992; Remis, 1994, 1998; Sarmiento, 1994; Goldsmith, 1996, 1999; Sarmiento et al., 1996; Sarmiento and Marcus, 2000; Albrecht et al., 2003; Inouye, 2003; Leigh et al., 2003; Stumpf et al., 2003; Taylor, 2003; Taylor and Goldsmith, 2003; Jabbour, 2008).

Our results suggest that the major differences between eastern and western gorilla medial cuneiform morphology is explained functionally by increased evolutionary commitment to terrestrial plantigrady and arboreal prehensility, respectively. Eastern gorillas are characterized by a more distally oriented, proportionately smaller, and less mediolaterally curved hallucial facet than are western gorillas. These characteristics follow the predictions for a more stable, plantigrade hallux in eastern gorillas and a more mobile, prehensile hallux in western gorillas. For instance, in western gorillas the hallux is set in a more abducted position in relation to the tarsus, presumably enabling a larger range of hallucial motion to facilitate grasps on a wider range of arboreal supports. Alternatively, eastern gorillas have a more adducted set of the hallux with a smaller range of motion, but one that may provide more stability during terrestrial plantigrade push-off. These interpretations of gorilla functional morphology are further supported by the fact that chimpanzees and bonobos also display a medial cuneiform anatomy that is most similar to that of western gorillas in terms of our functional predictions (Table 8 and Fig. 10) (Schultz, 1930, 1934; Gomberg, 1981). An additional characteristic that differentiates eastern from western gorillas, but was not part of our functional predictions, is a medial cuneiform that is more wedged into the intermediate cuneiform and second metatarsal, particularly more dorsally (Figs. 1-3), perhaps providing additional stability to the distomedial tarsometatarsal region during terrestrial locomotion.

Recall that grauer gorillas do not differ from mountain gorillas in ways that follow our a priori functional predictions. However, our sample of grauer gorillas derives mostly from known highland localities and further studies that include more lowland grauer gorillas appear warranted. Despite this, several features of the medial cuneiform still make it relatively straightforward to distinguish grauer from mountain gorillas. All three angles involving the navicular facet and the relative areas of the navicular and second metatarsal facets serve to separate these two taxa (Figs. 3, 4, 6, and 9). Thus, the distinguishing characteristics of these two taxa appear unrelated to differences in hallucial abduction ability and frequency of arboreality, and require an alternative explanation. These results are similar to those reported on dental and craniomandibular features; grauer gorillas do not appear to be morphologically intermediate between western and mountain gorillas, as might be predicted by dietary expectations given their feeding ecology (Uchida, 1998; Taylor, 2003).

Over the years, evidence has accumulated that suggests brief periods of genetic contact between western and grauer gorillas, certainly during the Pleistocene (Groves and Stott, 1979; Groves, 2001; Thalmann et al., 2005, 2007) and even perhaps as late as the Holocene, which is consistent with the model proposed by Ackermann and Bishop (2010). For instance, one female and two male gorillas collected in 1898 from Bondo-located in the Uele Valley of the Democratic Republic of Congo (north-central), roughly midway between current distributions of eastern and western gorillas-have hinted at this possibility for over a century (Coolidge, 1929, 1936; Groves, 1967). Morphologically, these specimens look like western gorillas (Coolidge, 1929; Groves, 1967, 2003; Albrecht

Table 8

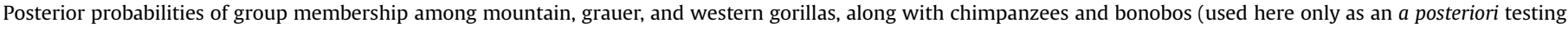
sample) using three angles, one relative area, and one curvature (correct classifications emphasized in bold face).

\begin{tabular}{|c|c|c|c|c|c|c|c|c|c|}
\hline & \multicolumn{3}{|c|}{ Classification Sample } & & \multicolumn{5}{|c|}{ Testing Sample } \\
\hline & Mountain & Grauer & Western & & Mountain & Grauer & Western & Chimpanzees & Bonobos \\
\hline Mountain & 10 & 2 & 1 & Mountain & 3 & 1 & 0 & 5 & 4 \\
\hline$\%$ & 76.9 & 15.4 & 7.7 & $\%$ & 75.0 & 25.0 & 0.0 & 26.3 & 18.2 \\
\hline Grauer & 1 & 11 & 1 & Grauer & 0 & $\mathbf{0}$ & 0 & 0 & 2 \\
\hline$\%$ & 7.7 & 84.6 & 7.7 & $\%$ & 0.0 & 0.0 & 0.0 & 0.0 & 9.1 \\
\hline Western & 1 & 2 & 11 & Western & 0 & 1 & 9 & 14 & 16 \\
\hline$\%$ & 7.7 & 14.3 & 78.6 & $\%$ & 0.0 & 10.0 & 90.0 & 73.7 & 72.7 \\
\hline
\end{tabular}


et al., 2003). Their provenance has occasionally been questioned, but given the very specific locality and collection information, it implies at least some recent geographical proximity between western and grauer gorillas (Groves, 1971). Analyses of gorilla genomic DNA suggests an east-west split beginning 0.9-1.6 million years ago with low levels of gene flow occurring mostly in an east to west direction until approximately 77,700 years ago (Thalmann et al., 2005, 2007). It has also been suggested by Ackermann and Bishop (2010), based on molecular and morphological evidence, that grauer gorillas may represent either a hybrid zone between mountain and western gorillas or the homogenized product of one. These authors base their interpretation on the presence of supernumerary teeth and the malar suture at higher than expected frequencies in grauer gorillas, similar to that observed in hybrid baboons (Ackermann et al., 2006; Ackermann, 2007). Ackermann and Bishop's (2010) suggestion of hybridization is relevant to the present study because we sampled many of the same grauer gorillas as they did and several of these also display clear evidence of osseous and non-osseous tarsal coalitions between the navicular and intermediate cuneiform. This is a particularly rare form of navicular-cuneiform coalition in humans (Burnett and Case, 2005) and Ackermann and Bishop (2010: 10) argue that high frequencies of otherwise rare non-metric characters

"may indicate a breakdown in the coordination of early development associated with the mixing of evolutionarily divergent genotypes/phenotypes (Ackermann et al., 2006; Ackermann, 2007). This is especially true as abnormal traits that appear in hybrid offspring but not in parental animals are generally considered to be the result of mixing two separately co-adapted gene complexes (Falconer and Mackay, 1997; Vrana et al. 2000), with hybridization resulting in the breakdown of these complexes (Dobzhansky and Pavlovsky, 1958; Templeton, 1987)."

Although tarsal coalitions in gorillas and other taxa require more systematic study and analysis, it must be considered that the observation of several instances of navicular-intermediate cuneiform coalition in grauer gorillas may have an impact on the distinct medial cuneiform shape that we observed. For instance, grauer gorillas differ from mountain gorillas primarily in variables that involve the navicular facet. The three angles between the navicular facet and the intermediate cuneiform (Fig. 3C), second metatarsal (Fig. 3E), and hallucial facets (Fig. 3D), and the relative area of the navicular facet (Fig. 4D) drive the separation of the eastern gorilla taxa, along with the relative area of the second metatarsal facet (Fig. 4C), which is reduced in grauer relative to mountain gorillas. Tarsal (and carpal) coalitions in modern humans are often asymptomatic with regard to foot (and hand) function (Kumai et al., 1996; Burnett and Case, 2005) and probably have little relevance in terms of gorilla functional morphology, but may provide a non-adaptive explanation for the observed differences between mountain and grauer gorilla medial cuneiform anatomy. Thus, we think that the high frequency of coalition of the navicular and intermediate cuneiform in grauer gorillas is currently the best hypothesis to explain the distinctive features observed in their medial cuneiform morphology. Whether these differences are indeed the result of hybridization or some other evolutionary process, such as inbreeding or a recent population bottleneck, warrants further investigation (Jensen-Seaman and Kidd, 2001; Leigh et al., 2003; Ackermann and Bishop, 2010). However, there is little doubt that both eastern gorillas studied herein differ from western gorillas in similar ways that are consistent with functional predictions of a more terrestrially-adapted hallux as opposed to one adapted to more prehensile, climbing-related behaviors.

Because gorillas are a monophyletic group, it appears that medial cuneiform morphology has evolved considerably over time given its present diversity in modern gorillas. Further comparative work should attempt to resolve whether the primitive condition for the genus was more like that in modern eastern or western gorillas, or perhaps neither. Our multivariate comparisons of specific morphological features related to hallux prehensility in gorillas, chimpanzees, and bonobos show that western gorillas are most similar to Pan in terms of these features (Fig. 10). Previous work has also suggested more similarities in medial cuneiform anatomy between western gorillas and chimpanzees (Schultz, 1930, 1934; Gomberg, 1981). Together, these observations suggest that eastern gorillas have derived their medial cuneiform anatomy from a more prehensile recent ancestry, but more work across hominoids and other primates is needed to resolve this issue. Even more importantly, the fossil record of ancient and recent gorillas needs to increase substantially in order to provide a better understanding of these and other fascinating issues in gorilla evolution (Pickford and Senut, 2005; Suwa et al., 2007).

Since it was first suggested that more mtDNA variation was present in gorillas than in the two recognized species of Pan (Ruvolo et al., 1994), there has been considerable study and discussion regarding the taxonomic and genetic diversity of gorillas (Garner and Ryder, 1996; Ruvolo, 1997; Saltonstall et al., 1998; Gagneux et al., 1999; Groves, 2000, 2001, 2003; Clifford et al., 2003; Jensen-Seaman et al., 2003; Thalmann et al., 2005, 2007; Anthony et al., 2007;). Subsequent molecular analyses have confirmed the mtDNA distinction between eastern and western gorillas (Garner and Ryder, 1996; Jensen-Seaman et al., 2003; Oates et al., 2003; Anthony et al., 2007), but work on the nuclear genome of gorillas has not shown the same level of difference as is recognized between chimpanzees and bonobos (Jensen-Seaman et al., 2003; Thalmann et al., 2007). The results of this study have obvious implications for interpreting functional morphology and adaptation in eastern and western gorillas, but these results also have important implications for interpretations of gorilla systematics and evolutionary history. Differences in gorilla morphology, including features of the medial cuneiform, prompted Schultz $(1930,1934)$ to recognize two distinct species of gorillas. In contrast, others suggest that despite statistical differences between gorilla taxa in traditional morphometric analyses, overall levels of morphological variation among gorilla taxa are actually lower than would be expected for multiple species (Leigh et al., 2003). Our results add to a growing corpus of morphological and molecular data that easily distinguishes eastern from western gorillas, as well as mountain from grauer gorillas (Taylor and Goldsmith, 2003), and lends additional support to the designation of at least two species of gorilla: G. beringei in the east, and G. gorilla in the west. More importantly, however, our results support a hypothesis of adaptive divergence in terms of hallucial abduction ability relative to differing ecological habitats that may be longstanding within the respective lineages of eastern and western gorillas, while recognizing that probable low to medium levels of gene flow likely occurred between western and grauer gorillas throughout much of the Pleistocene (Thalmann et al., 2007).

Groves (1971) suggested that eastern gorillas occupied a more extensively distributed habitat of montane forest prior to the last glacial maximum $(\sim 0.02 \mathrm{Ma})$. Since that time, these habitats have reduced considerably due to warming and suggest that grauer gorillas may represent a more recent expansion of eastern gorillas into newly expanding lowland habitats (Groves, 1971). Subsequent studies of gorilla morphology, including this one, lend support to this hypothesis of dispersal (Leigh et al., 2003; Taylor, 2003), as do recent molecular studies (Jensen-Seaman and Kidd, 2001; Anthony et al., 2007). Our results suggest that if the more terrestrial adaptations present in the medial cuneiform of modern eastern gorillas are apomorphic within the genus, then these 
features probably evolved after gorillas first expanded into more montane environments, which may have occurred well before the last glacial period (i.e., before 0.1 Ma) (Groves, 1971). Alternatively, gorillas may have originated as a montane forest-dwelling species (Groves, 1971), and as such western gorillas may have evolved apomorphic medial cuneiform morphology due to past expansion during the mid to late Pleistocene into more continuously forested environments. In either case, it appears unlikely that the distinctive medial cuneiform anatomy that distinguishes eastern and western gorillas from one another has evolved since the last glacial maximum, and is more likely to represent a longstanding adaptive divergence between the two lineages. Various molecular estimates for the divergence of eastern and western gorillas typically converge within the Pleistocene, with some suggesting earlier divergence times and others more recent ones within the epoch (Ruvolo, 1996; Jensen-Seaman et al., 2003; Thalmann et al., 2005, 2007; Anthony et al., 2007). Further morphological, molecular, and fossil evidence should help to resolve this issue.

\section{Acknowledgements}

This research was supported by a Wenner-Gren Foundation post-PhD grant to MWT (Grant Number 7822). Curatorial assistance and access to museum collections provided by Dr. Richard Thorington and Linda Gordon (USNM), Dr. Emmanuel Gilissen and Wim Wendelen (RMCA), and Ned Gilmore (ANSP), is gratefully acknowledged. We also thank SIEMENS for generously donating to the USNM the Somatom Emotion CT scanner used in this work and three anonymous reviewers for their helpful and constructive criticisms of an earlier version of this manuscript.

\section{References}

Ackermann, R.R., 2007. Craniofacial variation and developmental divergence in primate and human evolution. In: Bock, G., Goode, J. (Eds.), Tinkering: The Microevolution of Development. Wiley, Chichester, United Kingdom, pp. 262-279.

Ackermann, R.R., Bishop, J.M., 2010. Morphological and molecular evidence reveals recent hybridization between gorilla taxa. Evolution 64, 271-290.

Ackermann, R.R., Rogers, J., Cheverud, J., 2006. Identifying the morphological signatures of hybridization in primate and human evolution. J. Hum. Evol. 51, 632-645.

Albrecht, G.H., Gelvin, B.R., Miller, J.A., 2003. The hierarchy of intraspecific variation in gorillas: a population-thinking approach with implications for fossil specied recognition studies. In: Taylor, A.B., Goldsmith, M.L. (Eds.), Gorilla Biology: a Multidisciplinary Perspective. Cambridge University Press, Cambridge, United Kingdom, pp. 62-103.

Anthony, N.M., Johnson-Bawe, M., Jeffery, K., Clifford, S.L., Abernethy, K.A., Tutin, C.E., Lahm, S.A., White, L.J.T., Utley, J.F., Wickings, E.J., Bruford, M.W., 2007. The role of Pleistocene refugia and rivers in shaping gorilla genetic diversity in central Africa. Proc. Natl. Acad. Sci. 104, 20432-20436.

Burnett, S.E., Case, D.T., 2005. Naviculo-cuneiform I coalition: evidence of significant differences in tarsal coalition frequency. The Foot 15, 80-85.

Casimir, M.J., 1975. Feeding ecology and nutrition of an eastern gorilla group in the Mt. Kahuzi region (Republic of Zaire). Folia Primatol. 24, 81-136.

Clifford, S.L., Abernethy, K.A., White, L.J.T., Tutin, C.E.G., Bruford, M.W., Wickings, E.J 2003. Genetic studies of western gorillas. In: Taylor, A.B., Goldsmith, M.L. (Eds.), Gorilla Biology: a Multidisciplinary Perspective. Cambridge University Press, Cambridge, United Kingdom, pp. 269-292.

Coolidge, H.J., 1929. A revision of the genus Gorilla. Mem. Mus. Comp. Zoolog. Harv. $50,291-381$.

Coolidge, H.J., 1936. Zoological results of the George Vanderbilt African Expedition of 1934. 4, notes on four gorillas from the Sanga River region. Proc. Acad. Nat. Sci. Philadelphia 88, 479-501.

Dobzhansky, T., Pavlovsky, O., 1958. Interracial hybridization and breakdown of coadapted gene complexes in Drosophila paulistorum and Drosophila willistoni. Proc. Natl. Acad. Sci. 44, 622-629.

Doran, D.M., 1996. Comparative positional behavior of the African apes. In: McGrew, W.C., Marchant, L.F., Nishida, T. (Eds.), Great Ape Societies. University Press, Cambridge, pp. 213-224.

Doran, D.M., Hunt, K.D., 1994. Comparative locomotor behavior of chimpanzees and bonobos: species and habitat differences. In: Wrangham, R.W., McGrew, W.C. de Waal, F.B., Heltne, P.G. (Eds.), Chimpanzee Cultures. Harvard University Press, Cambridge, Massachusetts, pp. 93-106.

Doran, D.M., McNeilage, A., 1998. Gorilla ecology and behavior. Evol. Anthropol. 6, 120-131.
Doran, D.M., McNeilage, A., 2001. Subspecific variation in gorilla behavior: the influence of ecological and social factors. In: Robbins, M.M., Sicotte, P., Stewart, K.J. (Eds.), Mountain Gorillas, Three Decades of Research at Karisoke. Cambridge University Press, Cambridge, pp. 123-149.

Efron, B., Tibshirani, R.J., 1993. An Introduction to the Bootstrap. CRC Press, LLC, Boca Raton, Florida.

Falconer, D.S., Mackay, T.F.C., 1997. Introduction to Quantitative Genetics. Dover Publications, New York, New York.

Falsetti, A.B., Jungers, W.L., Cole, T.M.I., 1993. Morphometrics of the callitrichid forelimb: a case study in size and shape. Int. J. Primatol. 14, 551-571.

Fossey, D., Harcourt, A.H., 1977. Feeding ecology of the free-ranging mountain gorillas. In: Clutton-Brock, T.H. (Ed.), Primate Ecology. Academic Press, London, pp. $415-449$.

Gagneux, P., Wills, C., Gerloff, U., Tautz, D., Morin, P.A., Boesch, C., Fruth, B., Hohmann, G., Ryder, O.A., Woodruff, D.S., 1999. Mitochondrial sequences show diverse evolutionary histories of African hominoids. Proc. Natl. Acad. Sci. 96, 5077-5082.

Garner, K.J., Ryder, O.A., 1996. Mitochondrial DNA diversity in gorillas. Mol. Phylogenet. Evol. 6, 39-48.

Gebo, D.L., 1992. Plantigrady and foot adaptation in African apes: implications for hominid origins. Am. J. Phys. Anthropol. 89, 29-58.

Goldsmith, M.L., 1996. Ecological influences on the ranging and grouping behavior of western lowland gorillas at Bai Hoköu, Central African Republic, Ph.D. Dissertation, State University of New York at Stony Brook.

Goldsmith, M.L., 1999. Ecological constraints on the foraging effort of western gorillas (Gorilla gorilla gorilla) at Bai Hoköu, Central African Republic. Int. J. Primatol. 20, 1-24.

Gomberg, D.N., 1981. Form and function of the hominoid foot, Ph.D. Dissertation, University of Massachusetts.

Goodall, A.J., Groves, C.P., 1977. The conservation of the eastern gorillas. In: Prince Rainier III, H.R.H., Bourne, G.H. (Eds.), Primate Conservation. Academic Press, New York, pp. 599-637.

Groves, C.P., 1967. Ecology and taxonomy of the gorilla. Nature 213, 890-893.

Groves, C.P., 1970. Population systematics of the gorilla. J. Zool. 161, 287-300.

Groves, C.P., 1971. Distribution and place of origin of the gorilla. Man 6, 44-51.

Groves, C.P., 2000. What, if anything, is taxonomy? Gorilla J. 21, 12-15.

Groves, C.P., 2001. Primate Taxonomy. Smithsonian Institution Press, Washington, DC.

Groves, C.P., 2003. A history of gorilla taxonomy. In: Taylor, A.B., Goldsmith, M.L. (Eds.), Gorilla Biology: a Multidisciplinary Perspective. Cambridge University Press, Cambridge, United Kingdom, pp. 15-34.

Groves, C.P., Stott, K.W.J., 1979. Systematic relationships of gorillas from Kahuzi, Tshiaberimu and Kayonza. Folia Primatol. 32, 161-179.

Hammer, Ø., Harper, D.A.T. (Eds.), 2006. Paleontological Data Analysis. Blackwell Publishing Ltd, Malden, Massachusetts.

Harcourt-Smith, W.E.H., 2002. Form and function in the hominoid tarsal skeleton, Ph.D. Dissertation, University of London.

Holm, S., 1979. A simple sequentially rejective multiple test procedure. Scand. J. Stat. $6,65-70$.

Hunt, K.D., 1991. Positional behavior in the hominoidea. Int. J. Primatol. 12, 95-118. Hunt, K.D., 1992. Positional behavior of Pan troglodytes in the Mahale mountains and Gombe stream national parks, Tanzania. Am. J. Phys. Anthropol. 87, 83-105.

Inouye, S.E., 2003. Intraspecific and ontogenetic variation in the forelimb morphology of Gorilla. In: Taylor, A.B., Goldsmith, M.L. (Eds.), Gorilla Biology: a Multidisciplinary Perspective. Cambridge University Press, Cambridge, United Kingdom, pp. 194-235.

Jabbour, R.S., 2008. Geographic variation in the forelimb and hindlimb skeletons of African apes, Ph.D. Dissertation, City University of New York.

Jensen-Seaman, M.I., Deinard, A.S., Kidd, K.K., 2003. Mitochondrial and nuclear DNA estimates of divergence between western and eastern gorillas. In: Taylor, A.B., Goldsmith, M.L. (Eds.), Gorilla Biology: a Multidisciplinary Perspective. Cambridge University Press, Cambridge, United Kingdom, pp. 247-268.

Jensen-Seaman, M.I., Kidd, K.K., 2001. Mitochondrial DNA variation and biogeography of eastern gorillas. Mol. Ecol. 10, 2241-2247.

Johnson, R.A., Wichern, D.W., 2002. Applied Multivariate Statistical Analysis, fifth ed. Prentice-Hall, Inc, Upper Saddle River, New Jersey.

Jungers, W.L., Falsetti, A.B., Wall, C.E., 1995. Shape, relative size, and size-adjustments in morphometrics. Yearb. Phys. Anthropol. 38, 137-161.

Kumai, T., Tanaka, Y., Takahura, Y., Tamai, S., 1996. Isolated first naviculo-cuneiform joint coalition. Foot Ankle Int. 17, 635-640.

Langdon, J.H., 1986. Functional Morphology of the Miocene Hominoid Foot. Karger, New York.

Leigh, S.R., Relethford, J.H., Park, P.B., Konigsberg, L.W., 2003. Morphological differentiation of Gorilla subspecies. In: Taylor, A.B., Goldsmith, M.L. (Eds.), Gorilla Biology, a Multidisciplinary Perspective. Cambridge University Press, Cambridge, United Kingdom, pp. 104-131.

Manly, B.F.J., 1997. Randomization, Bootstrap and Monte Carlo Methods in Biology, second ed. CRC Press, LLC, Boca Raton, Florida.

Marzke, M.W., Tocheri, M.W., Steinberg, B., Femiani, J.C., Reece, S.P., Linsheid, R.L., Orr, C.M., Marzke, R.F., 2010. Comparative 3D quantitative analyses of trapeziometacarpal joint surface curvatures among living catarrhines and fossil hominins. Am. J. Phys. Anthropol. 141, 38-51.

McHenry, H.M., Jones, A.L., 2006. Hallucial convergence in early hominids. J. Hum. Evol. 50, 534-539.

Moriyama, K., 1985. Anthropoid pedal morphology: multivariate analysis and locomotor interpretations. In: Kondo, S. (Ed.), Primate Morphophysiology, 
Locomotor Analyses and Human Bipedalism. University of Tokyo Press, Tokyo, pp. $167-180$.

Mosimann, J.E., 1970. Size allometry: size and shape variables with characterizations of the log-normal and gamma distributions. J. Am. Stat. Assoc. 56, 930-945.

Oates, J.F., McFarland, K.L., Groves, J.L., Bergl, R.A., Linder, J.M., Disotell, T.R., 2003. The Cross River gorilla: natural history and status of a neglected and critically endangered subspecies. In: Taylor, A.B., Goldsmith, M.L. (Eds.), Gorilla Biology: a Multidisciplinary Perspective. Cambridge University Press, Cambridge, United Kingdom, pp. 472-497.

Pickford, M., Senut, B., 2005. Hominoid teeth with chimpanzee and gorilla-like features from the Miocene of Kenya: implications for the chronology of the apehuman divergence and biogeography of Miocene hominoids. Anthropol. Sci. 113, 95-102.

Remis, M.J., 1994. Feeding ecology and positional behavior of western lowland gorillas (Gorilla gorilla gorilla) in the Central African Republic, Ph.D. Dissertation, Yale University.

Remis, M.J., 1998. The gorilla paradox: effects of habitat and body size on the positional behavior of lowland and mountain gorillas. In: Strasser, E., Fleagle, J.G.H., Rosenberger, A., McHenry, H.M. (Eds.), Primate Locomotion. Plenum Press, New York, pp. 95-106.

Rice, W.R., 1989. Analyzing tables of statistical tests. Evolution 43, 223-225.

Ruvolo, M., 1996. A new approach to studying modern human origins: hypothesis testing with coalescence time distributions. Mol. Phylogenet. Evol. 5, 202-219.

Ruvolo, M., 1997. Genetic diversity in hominoid primates. A. Rev. Anthropol. 26 $515-540$.

Ruvolo, M., Pan, D., Zehr, S., Goldberg, T., Disotell, T.R., von Durnum, M., 1994. Gene trees and hominoid phylogeny. Proc. Natl. Acad. Sci. 91, 8900-8904.

Saltonstall, K., Amato, G., Powell, J., 1998. Mitochondrial DNA variability in Grauer's gorillas of Kahuzi-Biega National Park. J. Hered. 89, 129-135.

Sarmiento, E.E., 1994. Terrestrial traits in the hands and feet of gorillas. Am. Mus. Novit. 3091, 1-56.

Sarmiento, E.E., Butynski, T.M., Kalina, J., 1996. Gorillas of Bwindi-Impenetrable Forest and the Virunga Volcanoes: taxonomic implications of morphological and ecological differences. Am. J. Primatol. 40,1-21.

Sarmiento, E.E., Marcus, L.F., 2000. The os navicular of humans, great apes, $\mathrm{OH} 8$, Hadar, and Oreopithecus: function, phylogeny, and multivariate analyses. Am. Mus. Novit. 3288, 1-38.

SAS Institute, 2002. Copyright (C) 2002-2003 SAS Institute Inc., SAS and all other SAS Institute Inc. product or service names are registered trademarks or trademarks of SAS Institute Inc., Cary, North Carolina, USA.

Schaller, G.B., 1963. The Mountain Gorilla, Ecology and Behavior. The University of Chicago Press, Chicago.

Schultz, A.H., 1930. The skeleton of the trunk and limbs of higher primates. Hum. Biol. 2, 303-438.

Schultz, A.H., 1934. Some distinguishing characters of the mountain gorilla. J. Mammal. 15, 51-61.

StatSoft, 2010. STATISTICA (data analysis software system), version 9. www. statsoft.com.

Stumpf, R.M., Polk, J.D., Oates, J.F., Jungers, W.L., Heesy, C.P., Groves, C.P., Fleagle, J.G., 2003. Patterns of diversity in gorilla cranial morphology. In: Taylor, A.B., Goldsmith, M.L. (Eds.), Gorilla Biology: a Multidisciplinary Perspective. Cambridge University Press, Cambridge, United Kingdom, pp. 35-61.

Suwa, G., Kono, R.T., Katoh, S., Asfaw, B., Beyene, Y., 2007. A new species of great ape from the late Miocene epoch in Ethiopia. Nature 448, 921-924.

Taylor, A.B., 2003. Ontogeny and function of the masticatory complex in Gorilla: functional, evolutionary, and taxonomic implications. In: Taylor, A.B., Goldsmith, M.L. (Eds.), Gorilla Biology: a Multidisciplinary Perspective. Cambridge University Press, Cambridge, United Kingdom, pp. 132-193.

Taylor, A.B., Goldsmith, M.L. (Eds.), 2003. Gorilla Biology: a Multidisciplinary Perspective. Cambridge University Press, Cambridge, United Kingdom.

Templeton, A.R., 1987. Inferences on natural population structure from genetic studies of captive mammalian populations. In: Chepko-Sade, B.D., Halpin, Z.T.
(Eds.), Mammalian Dispersal Patterns. University of Chicago Press, Chicago, Illinois, pp. 257-272.

Thalmann, O., Fischer, A., Lankester, F., Paabo, S., Vigilant, L., 2007. The complex evolutionary history of gorillas: insights from genomic data. Mol. Biol. Evol. 24 $146-158$.

Thalmann, O., Serre, D., Hofreiter, M., Lukas, D., Eriksson, J., Vigilant, L., 2005. Nuclear insertions help and hinder inference of the evolutionary history of gorilla mtDNA. Mol. Ecol. 14, 179-188.

Tocheri, M.W., 2007. Three-dimensional Riddles of the Radial Wrist: derived carpal and carpometacarpal joint morphology in the genus Homo and the implications for understanding the evolution of stone tool-related behaviors in hominins, Ph.D. Dissertation, Arizona State University.

Tocheri, M.W., 2009. Laser scanning: 3D analysis of biological surfaces. In: Sensen, C.W., Hallgrímsson, B. (Eds.), Advanced Imaging in Biology and Medicine. Springer-Verlag, Berlin, pp. 85-101.

Tocheri, M.W., Marzke, M.W., Liu, D., Bae, M., Jones, G.P., Williams, R.C., Razdan, A. 2003. Functional capabilities of modern and fossil hominid hands: threedimensional analysis of trapezia. Am. J. Phys. Anthropol. 122, 101-112.

Tocheri, M.W., Razdan, A., Williams, R.C., Marzke, M.W., 2005. A 3D quantitative comparison of trapezium and trapezoid relative articular and nonarticular surface areas in modern humans and great apes. J. Hum. Evol. 49, 570-586.

Tocheri, M.W., Orr, C.M., Larson, S.G., Sutikna, T., Jatmiko, Saptomo, E.W., Awe Due, R., Djubiantono, T., Morwood, M.J., Jungers, W.L., 2007. The primitive wrist of Homo floresiensis and its implications for hominin evolution. Science 317, 1743-1745.

Tocheri, M.W., Orr, C.M., Jacofsky, M.C., Marzke, M.W., 2008. The evolutionary history of the hominin hand since the last common ancestor of Pan and Homo. J. Anat. 212, 544-562.

Tutin, C.E.G., Fernandez, M., 1993. Composition of the diet of chimpanzees and comparisons with that of sympatric lowland gorillas in the Lopé Reserve, Gabon. Am. J. Primatol. 30, 195-211.

Tutin, C.E.G., Fernandez, M., Rogers, M.E., Williamson, E.A., McGrew, M.C., 1991 Foraging profiles of sympatric lowland gorillas and chimpanzees in the Lopé Reserve, Gabon. Phil. Trans. R. Soc. 334, 179-186.

Tuttle, R.H., 1970. Postural, propulsive, and prehensile capabilities in the cheiridia of chimpanzees and other great apes. In: Bourne, G.H. (Ed.), The Chimpanzee, vol. 2. Karger, Basel, New York, pp. 167-253.

Tuttle, R.H., 2003. An introductory persective: gorillas-how important, how many how long? In: Taylor, A.B., Goldsmith, M.L. (Eds.), Gorilla Biology: a Multidisciplinary Perspective. Cambridge University Press, Cambridge, United Kingdom, pp. 11-14.

Tuttle, R.H., Watts, D.P., 1985. The positional behavior and adaptive complexes of Pan gorilla. In: Kondo, S. (Ed.), Primate Morphophysiology, Locomotor Analyses and Human Bipedalism. University of Tokyo Press, Tokyo, pp. 261-288.

Uchida, A., 1996. What we don't know about great ape variation. Trends Ecol. Evol. $11,163-168$.

Uchida, A., 1998. Variation in tooth morphology of Gorilla gorilla. J. Hum. Evol. 34, 55-70.

Vrana, P.B., Fossella, J.A., Matteson, P., del Rio, T., O’Neill, M.J., Tilghman, S.M., 2000. Genetic and epigenetic incompatibilities underlie hybrid dysgenesis in Peromyscus. Nat. Genet 25, 120-124.

Yamagiwa, J., Maruhashi, T., Yumoto, T., Mwanza, N., 1996. Dietary and ranging overlap in sympatric gorillas and chimpanzees in Kahuzi-Biega National Park, Zaire. In: McGrew, W.C., Marchant, L.F., Nishida, T. (Eds.), Great Ape Societies. Cambridge University Press, Cambridge, UK, pp. 82-98.

Yamagiwa, J., Mwanza, N., 1994. Day-journey length and daily diet of solitary male gorillas in lowland and highland habitats. Int. J. Primatol. 15, 207-224.

Yamagiwa, J., Mwanza, N., Yumoto, T., Maruhashi, I., 1992. Travel distances and food habits of eastern lowland gorillas: a comparative analysis. In: Itoigawa, N., Sugiyama, Y., Sackett, G.P., Thompson, R.K.R. (Eds.), Topics in Primatology. Tokyo University Press, Tokyo, pp. 267-281. 